\title{
Out of Context, in Association: Human Remains Salvaged from the Mini-athiliya Shell Midden, Sri Lanka
}

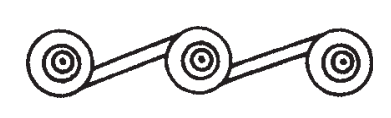

Samanti Kulatilake, Roshan D. Peiris, H. Nimal Perera, and H. Jude Perera

ABSTRACT

The skeletal evidence for early modern human occupation of South Asia is sparse. Sri Lanka has been occupied by modern humans from the terminal Pleistocene, with a skeletal record indicating continuity of occupation and settlement into the late Holocene. This study focuses on the analysis of fragmented human remains dated to the mid-Holocene recovered from a salvage archaeology operation conducted at a shell midden in the coastal village of Mini-athiliya in southern Sri Lanka. The Mini-athiliya site has been radiocarbon dated to ca. 3600 B.P. Large quantities of estuarine, marine, and terrestrial shells, stone tools, lithic debris, and animal bones were associated with the human skeletal remains recovered from this shell midden. The skeletal remains, faunal remains, and stone tools from this site have been greatly disturbed by recent shell mining activities. Much of the material collected from the piles of debris was mixed, fragmented, and out of context. Our study refers to associations we make to the cultural assemblage from this site to make inferences on the context of skeletal remains found. The minimum number of individuals (MNI) identified from commingled remains is five. In addition, another individual from an undisturbed context from this site was previously reported. Based on tooth eruption and the presence and level of dental attrition, the estimated age at death for these individuals ranges from 5 to 45 years. Heavy attrition in the adult dentition indicates a highly abrasive diet with a marked absence of caries among these relatively robust people. This study contributes to the understanding of the bioarchaeological aspects of mid-Holocene aquatic foragers who were contemporaries of early agricultural people of South Asia, while describing a framework for managing a skeletal sample from a disturbed context. KEYWORDS: shell midden, rescue archaeology, bioarchaeology, dental morphology, aquatic forager, mid-Holocene, Sri Lanka.

\footnotetext{
Samanti Kulatilake is an Associate Professor of Biological Anthropology at the Department of Sociology and Anthropology, Mount Royal University in Calgary, Canada. Roshan D. Peiris is a Professor of Anatomy at the Division of Anatomy, Department of Basic Sciences, Faculty of Dental Sciences, at the University of Peradeniya in Sri Lanka. H. Nimal Perera is the former Director of Excavations at the National Archaeology Department of Sri Lanka and is currently Consultant to the Postgraduate Institute of Archaeology in Sri Lanka. H. Jude Perera is affiliated with the Sri Lanka Department of Archaeology.
} 


\section{INTRODUCTION}

The region of South Asia has received consider able attention in the discussion of early dispersals of modern humans. While the skeletal record for anatomically modern human occupation of South Asia is generally sparse, Sri Lanka is a notable exception. Archaeological research in Sri Lanka over the last 150 years has yielded a wealth of important information. Modern humans have occupied Sri Lanka from the terminal Pleistocene, with early human remains from the island dated to 37,000 years ago (H.N. Perera 2010). People from the late Pleistocene to the mid-Holocene of Sri Lanka are commonly referred to as "Balangoda" people due to the discovery of numerous prehistoric archaeological sites from the Balangoda district of southern Sri Lanka. Archaeologically, these early hunter gatherer and aquatic forager populations are associated with the Mesolithic cultural tradition popularly known as the Balangoda culture (Deraniyagala 1992).

Early to mid-Holocene occupation of Sri Lanka is represented by several early agricultural proto-historic and historic sites and a series of shell midden sites in the southern parts of the island. Although many shell deposits encountered in the coastal regions of Sri Lanka are attributed to natural processes such as intermittent lowering of the sea levels during the mid-Holocene (Katupotha 1995), some shell patches and mounds classified as shell middens have long been recognized as a class of sites of archaeological significance. These sites include Pallemalala, Godawaya, and Miniathiliya, all located in the southern coastal belt of Sri Lanka (Deraniyagala 1958, 1992; H.N. Perera 2010).

This study focuses on the shell midden site of Mini-athiliya $\left(6^{\circ} 07^{\prime} 12^{\prime \prime} \mathrm{N}, 80^{\circ} 56^{\prime} 47^{\prime \prime} \mathrm{E}\right)$, near the town of Hungama (Fig. 1). Occasional human bones and teeth have been previously encountered and reported by villagers working in the Mini-athiliya paddy field and surrounding areas. Similar to shell midden exploitation occurring around the world (Ceci 1984), the Mini-athiliya shell midden has been recently mined for commercial purposes. During this mining operation, a village official had recognized human skeletal remains among the mined midden material. He alerted the National Archaeological Department and, under the direction of the third author, an excavation team was deployed to undertake an emergency salvage archaeology operation to rescue what was left of this site. The Hungama Mini-athiliya site and associated excavations are identified as HMA 2007-2008 (H.N. Perera 2009). The excavation team intercepted several piles of midden debris before they were sent to be crushed. During a follow-up systematic excavation at Mini-athiliya, a single undisturbed burial (HMA 6) dated to ca. 3600 B.P.was recovered (Kulatilake et al. 2014). Here we have taken on the challenge of sorting, identifying, describing, and analyzing the fragmented human remains recovered out of context from the piles of midden debris.

It is pertinent to note at the onset that most of the contextual data for the commingled remains are unavailable due to the nature of the rescue archaeology operation, which recovered only some information on the location of the human remains dug up by the shell miners (Fig. 2). Nonetheless, we describe the strategy we adopted to manage this highly disturbed context and assess the information we gleaned from limited and fragmented bioarchaeological material. Describing a rescue archaeology excavation conducted at a shell midden site in South Africa, Orton (2009) concludes that if the site had been discovered intact, it would have provided one of the best archaeological sequences in the area. Similarly, the loss of contextual 

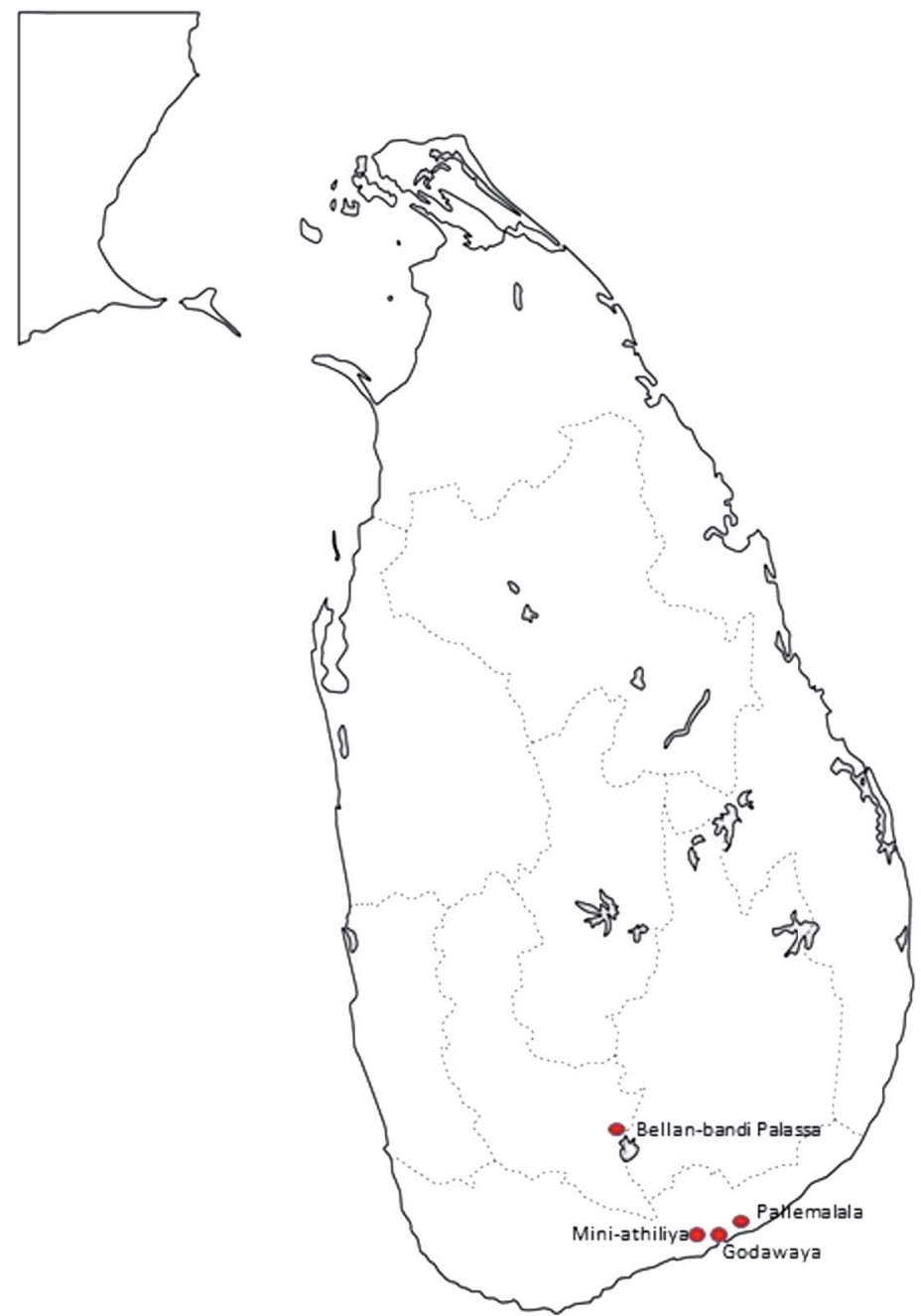

Fig. 1. Map of Sri Lanka showing the location of Mini-athiliya and other midden sites.

data precludes the application of more refined techniques of data recovery and analysis of the material from the salvage archaeology operation at Mini-athiliya. Throughout this article, we describe the limitations we encountered, offer some conclusions of which we are confident, and make further inferences that require further testing.

A major objective of this article is to describe the mid-Holocene people of Miniathiliya, as represented by the small sample identified from this site. The data, although limited by the nature of the disruption to the site, contributes to understanding the biological anthropology of people within this regional and chronological framework.

The human skeletal and dental sample from Mini-athiliya includes a minimum of five individuals identified from commingled midden remains. They are represented primarily by their dentition along with a few fragmented cranial and postcranial 


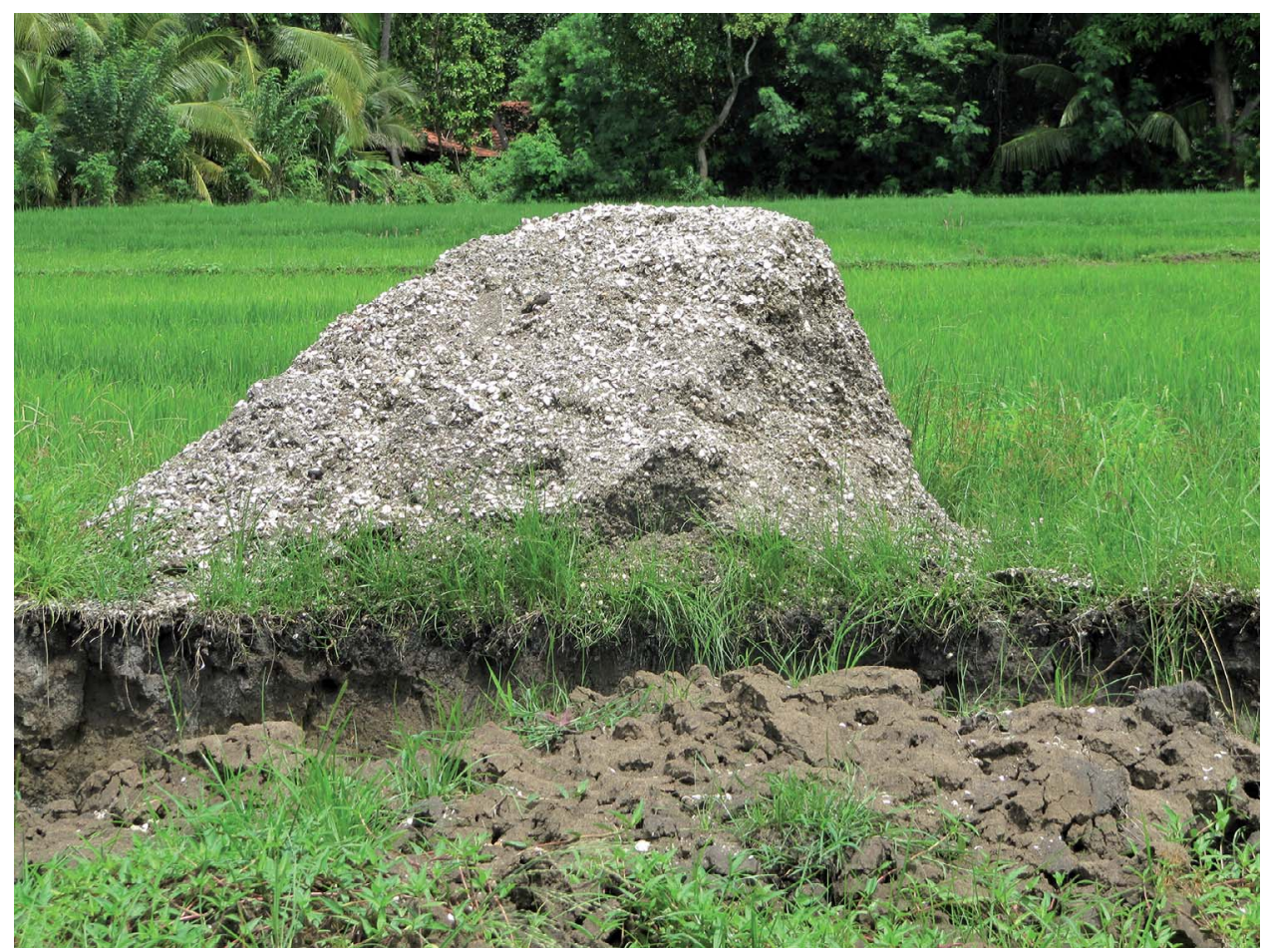

Fig. 2. A commercially dug up pile of shells at Mini-athiliya.

elements. In this study, we also describe the dentition of a sixth individual previously excavated in situ. We examine the types of bio-cultural adaptations of these coastal people as suggested by their dentition and skeletal remains and other lines of archaeological evidence from this site. As well, we assess the bioarchaeological evidence that places the Mini-athiliya skeletal assemblage within the context of other mid-Holocene people documented so far from the region.

THE MID-HOLOCENE ARCHAEOLOGICAL RECORD OF SOUTH ASIA: THE CHRONOLOGICAL CONTEXT FOR SHELL MIDDEN SITES IN SOUTHERN SRI LANKA

Few systematic survey and excavation reports of midden sites from peninsular South Asia are available. One such survey report documents midden deposits radiocarbon dated to ca. 7000 B.P. along the Indus delta (Sindh) and the coast of Las Bela (Balochistan), where chipped stone artifacts together with marine and mangrove shells were encountered (Biagi 2013). The shell accumulations and midden sites of Sri Lanka have garnered more attention, however; several studies have been conducted there since the late 1950s (Deraniyagala 1958; Kennedy 1965). The people associated with mid-Holocene shell midden sites from Sri Lanka have been described as hunter gatherers and aquatic foragers who used technological traditions that included microlithic tools; they seem to be indicative of the Mesolithic archaeological phase of South Asia (Deraniyagala 1992; Kennedy 2000). 
The Neolithic cultural phase is well-documented throughout the Holocene in peninsular South Asia. However, firm evidence of extensive early Neolithic settlements is not recorded from Sri Lanka (cf. Premathilake 2006). Mid-Holocene agricultural populations of South Asia and the people from the Harappan (Indus) civilization and associated sites have been the primary focus of numerous bioarchaeological and cemetery studies (Kennedy 1975, 1976, 2000; Lukacs 1984). Represented by cremated remains within urn burials and the associated megalithic cultural complex, early Iron Age agricultural people from the mid- to late Holocene of peninsular South Asia and Sri Lanka have also been of interest (Kennedy 1975, 2000). The contemporaries of those agricultural groups - the hunter-gatherer and aquatic forager populations - have received relatively little attention, primarily due to limited systematic archaeological investigations and hence a paucity of evidence. The absence of secure radiocarbon dates for many of these sites poses an additional challenge.

In the early to mid-Holocene archaeological record of Sri Lanka, Bellan-bandi Palassa $\left(6^{\circ} 31^{\prime} 0^{\prime \prime} \mathrm{N}, 80^{\circ} 47^{\prime} 60^{\prime \prime} \mathrm{E}\right)$, stands out as a well-documented site where people have subsisted on hunting and gathering as well as aquatic foraging. Located inland in the Balangoda district adjacent to a tributary of the Walawe River, this kitchen midden site has yielded the skeletal and dental remains of an estimated 30-35 individuals (Deraniyagala 1958; Deraniyagala and Kennedy 1972; Kanthilatha et al. 2012; Kennedy 2000; Kennedy and Elgart 1998). Some of these burials are described as being positioned as flexed burials with associated grave goods (Deraniyagala 1958). The skeletal remains are described as muscular and archaic by Kennedy $(1965,2000)$.

Multiple conflicting dates have been obtained for the Bellan-bandi Palassa site, partly due to the mixing of prehistoric and historic contexts of the site following natural processes and human activity, with the period of intensive habitation dated to ca. 12,000 B.P. (H.N. Perera 2010). This date is supported by a colluvial depositional history of long duration at the site (Simpson et al. 2008). Bellan-bandi Palassa has yielded a variety of artifacts including bifacial choppers, scrapers, cores, pitted and unpitted hammers, and microliths. Bone tools from Bellan-bandi Palassa include digging implements and bone points made out of antler and horn (Deraniyagala 1958, 1992). The faunal remains from Bellan-bandi Palassa's main habitation show a higher reliance on ungulates and the presence of a diverse array of small mammals including bones of domesticated dogs as well as shell species and a shark tooth (H.N. Perera 2010).

In the southern coastal region of Sri Lanka, many shell midden sites have been identified as conspicuous mounds and patches. These sites occur on the coastal stretch from Tangalle to Hambantota, as well as within Yala National Park in the southeastern quadrant of the island. Such sites often contain well-preserved cultural remains within stratigraphically stable deposits, representing primarily the food remnants of aquatic foragers (H.N. Perera 2009). The shell middens and habitations such as those located in Pallemalala, Godawaya, and Mini-athiliya have revealed a clear anthropogenic signature (Deraniyagala 1992; Karunaratne et al. 2016; Kulatilake 2009; Kulatilake et al. 2014; Somadeva and Ranasinghe 2006; Wahl n.d.).

From the Pallemalala shell midden in the Hambantota district $\left(06^{\circ} 11^{\prime} 18^{\prime \prime} \mathrm{N}, 81^{\circ} 10^{\prime} 06^{\prime \prime} \mathrm{E}\right)$, seven complete skeletons and fragments of six individuals were recovered (Somadeva and Ranasinghe 2006). Encountered primarily as flexed burials, these skeletal remains are described as having come from robust individuals, with dentition showing a high degree of attrition, but an absence of caries (Kulatilake 2012; 
Ranaweera 2002). The stone tool assemblage from Pallemalala includes a grindstone and microliths fashioned mainly from quartz. The faunal remains recovered from the Pallemalala shell midden represent diverse edible shell species, fish, and small mammals including monkeys and deer (Somadeva and Ranasinghe 2006). A firm radiometric date is unavailable for the Pallemalala shell midden site. Based on a date obtained by Katupotha (1988) from the shell deposit in this locale, the timeframe suggested for this site is estimated at $4050 \pm 60$ uncal. B.P.

The Godawaya site $\left(06^{\circ} 06^{\prime} 28^{\prime \prime} \mathrm{N}, 81^{\circ} 03^{\prime} 04^{\prime \prime} \mathrm{E}\right)$, located very close to the present coastline at the mouth of the Walawe River in southern Sri Lanka, has been attributed to the mid-Holocene. From an excavation carried out in 2007, this site has yielded the remains of three individuals (Wahl n.d.). A subsequent systematic horizontal excavation carried out at Godawaya yielded late Mesolithic stone tools, lithic debitage, and charred faunal remains including an occupational surface associated with the human remains recovered in the 2007 excavation (Karunaratne et al. 2016). A higher reliance on marine resources is indicated from the fish bones of shark, barracuda, and trevally present at Godawaya. The Godawaya site lacks evidence for the high exploitation of shell species, one of the primary food sources among the Pallemalala and Mini-athiliya people located further inland (Karunaratne et al. 2016; Kulatilake et al. 2014; Somadeva and Ranasinghe 2006). The faunal remains, artifacts and burial practices from the Pallemalala and Godawaya sites are similar to the finds and observations from Mini-athiliya.

Shell midden sites from Sri Lanka are dated from approximately 12,000 B.P. in the terminal Pleistocene or early Holocene to approximately 3000 B.P. After this time, agricultural groups appear to further dominate the landscape (Deraniyagala 1992; H.N. Perera 2010). The stratigraphic information from the upper levels of the Miniathiliya site indicate the recovery of wattle and daub remnants and pottery fragments (H.N. Perera 2009). This could either be due to mixing while the land was being tilled for paddy cultivation by recent agriculturalists or to early aquatic forager inhabitants sharing elements of material culture with their agricultural contemporaries. Modern day people of the region who subsist on fishing and agricultural activities do not specialize in collecting and consuming large amounts of shellfish. Further evidence from the region is required to shed more light on diffusion, shifting subsistence patterns, and cultural transitions.

\section{MATERIALS AND METHODS}

The excavation team that undertook the salvage archaeology operation at Miniathiliya noted that approximately 75 percent of the site, including several human burials, had been destroyed prior to their arrival (H.N. Perera 2009). However, their systematic archaeological excavation at the site uncovered an undisturbed skeleton of an adult male. Charcoal samples obtained from sealed contexts from this excavation yielded radiocarbon dates of $3680 \pm 40$ cal. B.P. and $3610 \pm 40 \mathrm{cal}$. B.P. (Kulatilake et al. 2014). In the absence of contextual data that would normally accompany a systematic excavation, we cautiously apply these dates to the associated midden material from the pits dug up during the mining process.

A rough estimate of the area of this well-contained midden is stated as $38 \mathrm{~m}^{2}$ and the weight of shells recovered is estimated at $40,000 \mathrm{~kg}$ (H.J. Perera 2012). The excavation team identified up to seven large pits dug up by the shell miners. These pits, scattered 
across the site, were labeled Pits 1-6 and Pit A. The soil, large quantities of shells, lithic debitage, and human and animal bones dug up and piled alongside each pit were intercepted and retained by the excavation team and transferred into large bags and boxes and labeled accordingly. Site details including maps, drawings, and photographs of provenance and stratigraphy were used to obtain additional contextual information to facilitate the sorting of commingled human remains.

Standard human osteological identification techniques were used to identify the commingled human remains. Stone tool debris and tools such as geometric microliths, flakes, hammerstones, and grinders, shells, and charred or fragmented animal bones and pottery fragments were identified and separated from the human remains (Bass 2005; Brothwell 1981; Buikstra and Ubelaker 1994; Ubelaker 1999; White et al. 2012). Bags and boxes labeled as containing material from Pits 1, 2, 5, 6 and Pit A yielded human remains. Only faunal remains and lithic debris were recovered from contents associated with Pits 3 and 4. Preliminary cleaning was carried out and the identifiable human bone fragments were separated according to element and side. The method described by White and colleagues (2012:337-338) was used to establish a minimum number of individuals (MNI). Taking age criteria into account, the paired and unpaired elements were used to sort, number, and establish the MNI. For the adult remains, the most numerous bone was the frontal bone. Also in the sample were skeletal and dental remains of a child. The highly fragmented postcranial elements, unless clearly articulated or closely associated with a particular set of cranial elements, were not assigned to any specific individual.

As detailed below, a careful assessment of all available skeletal elements (some of which were articulated) and teeth recovered from the shell miners' pits enabled us to establish that a minimum of five individuals were present (Table 1). They were labeled HMA 1, 2, 3, 4, and 5 (Kulatilake 2009). Where possible, cranial robusticity grades developed by Lahr (1996) were applied to describe the skeletal sample.

Due to the paucity of diagnostic elements, among the five individuals identified from the mixed debris, accurate sexing was not possible. However, the complete burial (HMA 6) recovered in situ included ossa coxae and cranial elements that enabled accurate sexing (Kulatilake et al. 2014).

Although the skeletal remains were highly fragmented and offered limited opportunities for morphometric study and analysis, the salvaged human teeth provided information on the demographics and dietary adaptations of these people. In this study, we describe the teeth of HMA 1-5 and HMA 6 (from the burial that was excavated separately). A total of 72 teeth, including 58 permanent teeth and 14 deciduous teeth, were recorded for this assemblage.

The second author, a trained and calibrated independent observer, recorded all metric and non-metric dental characteristics, thereby avoiding inter-observer error. The associated mandibles and maxillae were positioned for dental imaging with Cone Beam Computed Tomography (CBCT) scans. The CBCT scanner's rotating arm obtains up to 600 images for the reproduction of a three-dimensional image using associated software. While CBCT scanning is typically used on living subjects, we extended its usage to the morphometric study of the dental structures of the Mini-athiliya people. The CBCT scans and associated images allowed us to ascertain the dental eruption patterns of deciduous dentition and root morphology of the Mini-athiliya people. These scans also aided verification of recorded metric observations. 


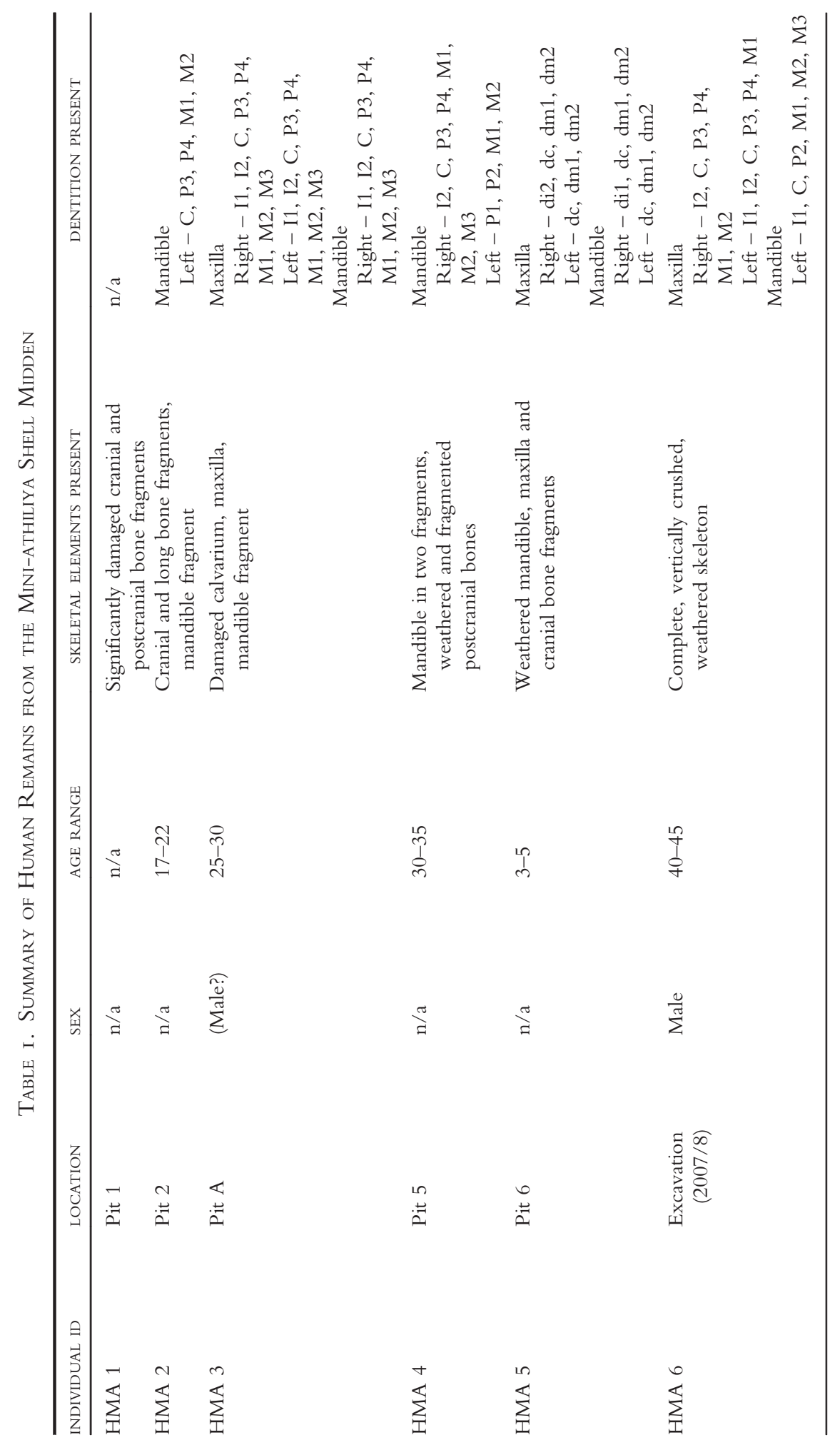




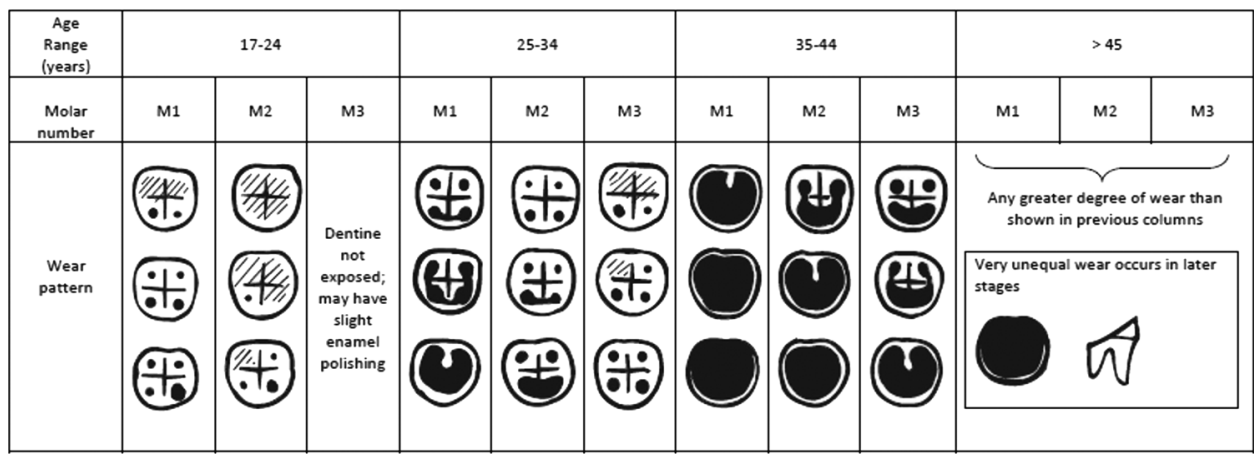

Fig. 3. Standards of occlusal wear of molar teeth for age estimation (after Brothwell 1981).

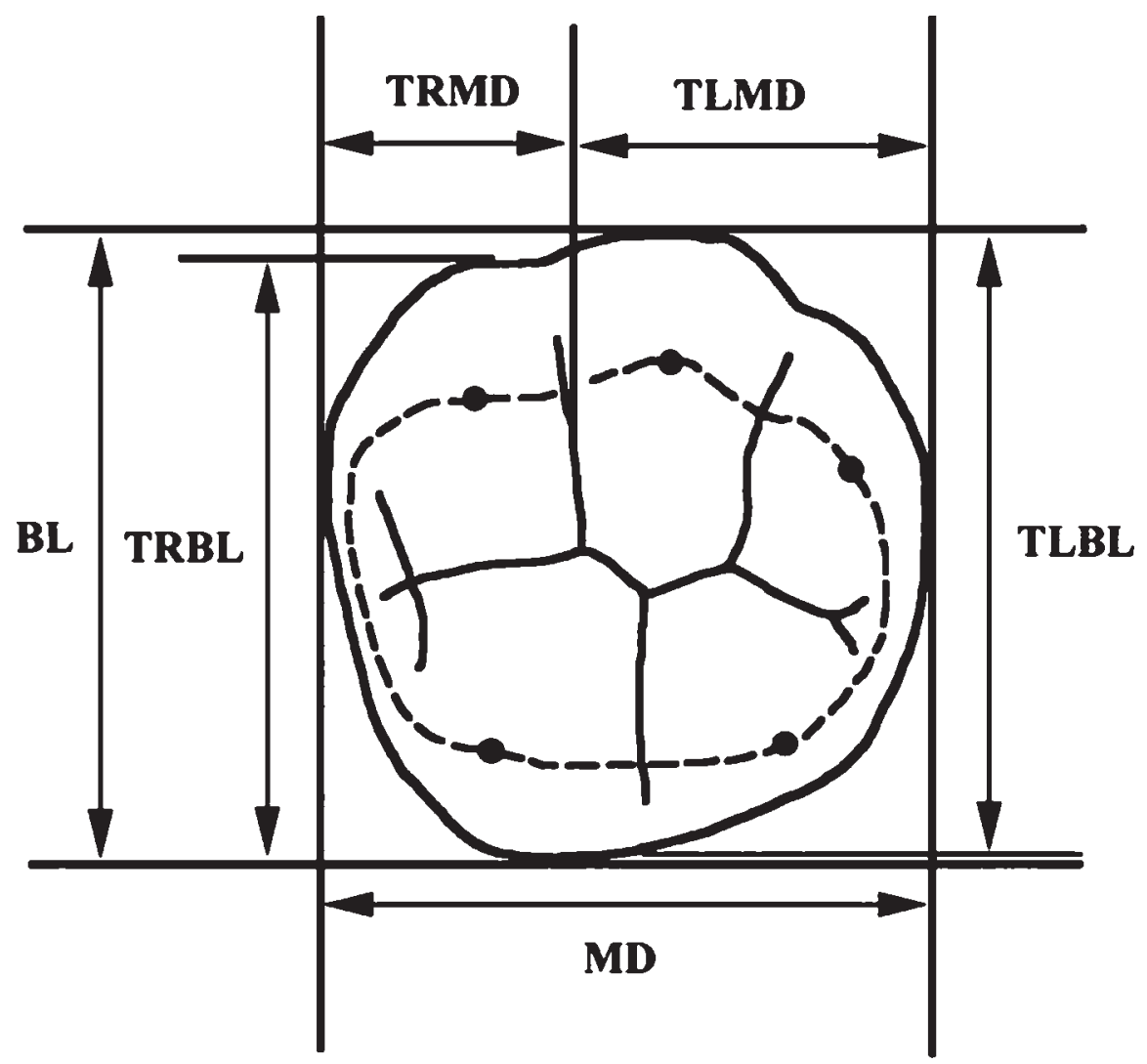

Fig. 4. Molar crown measurements. 


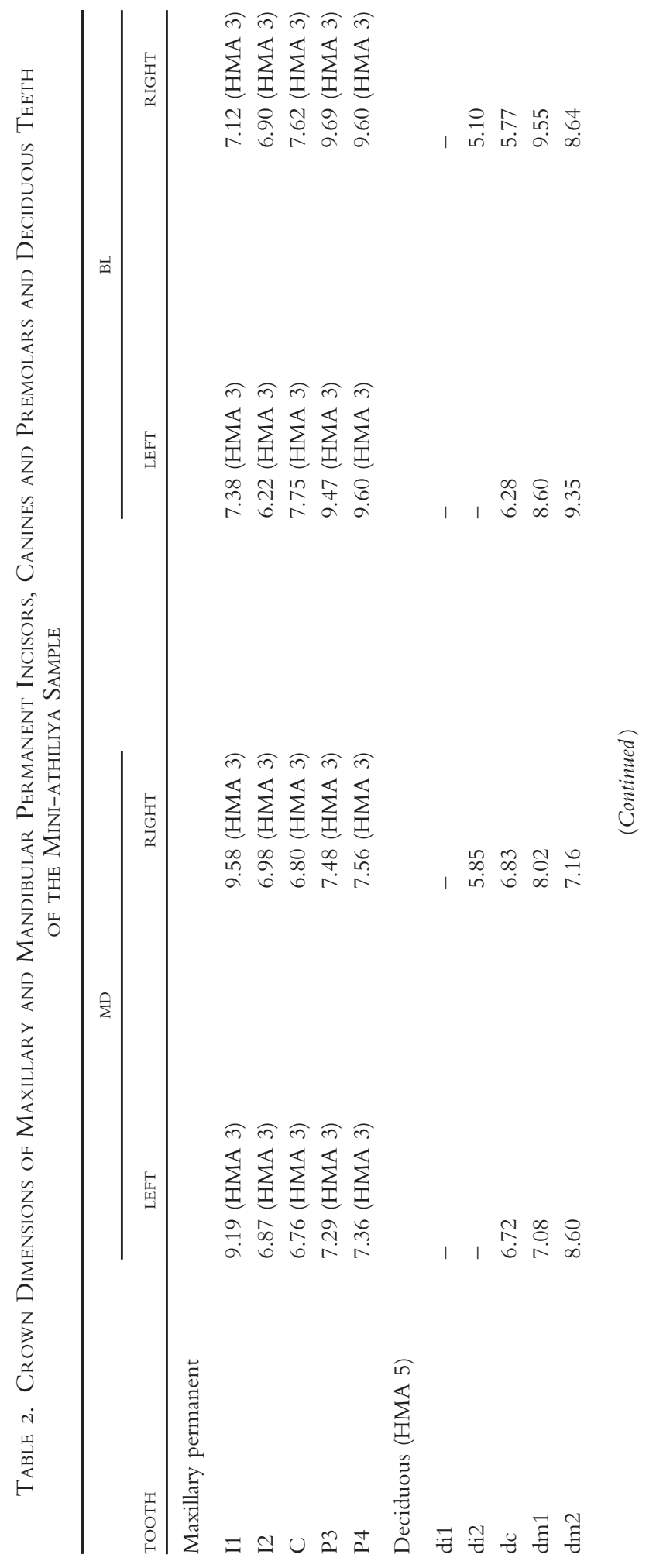




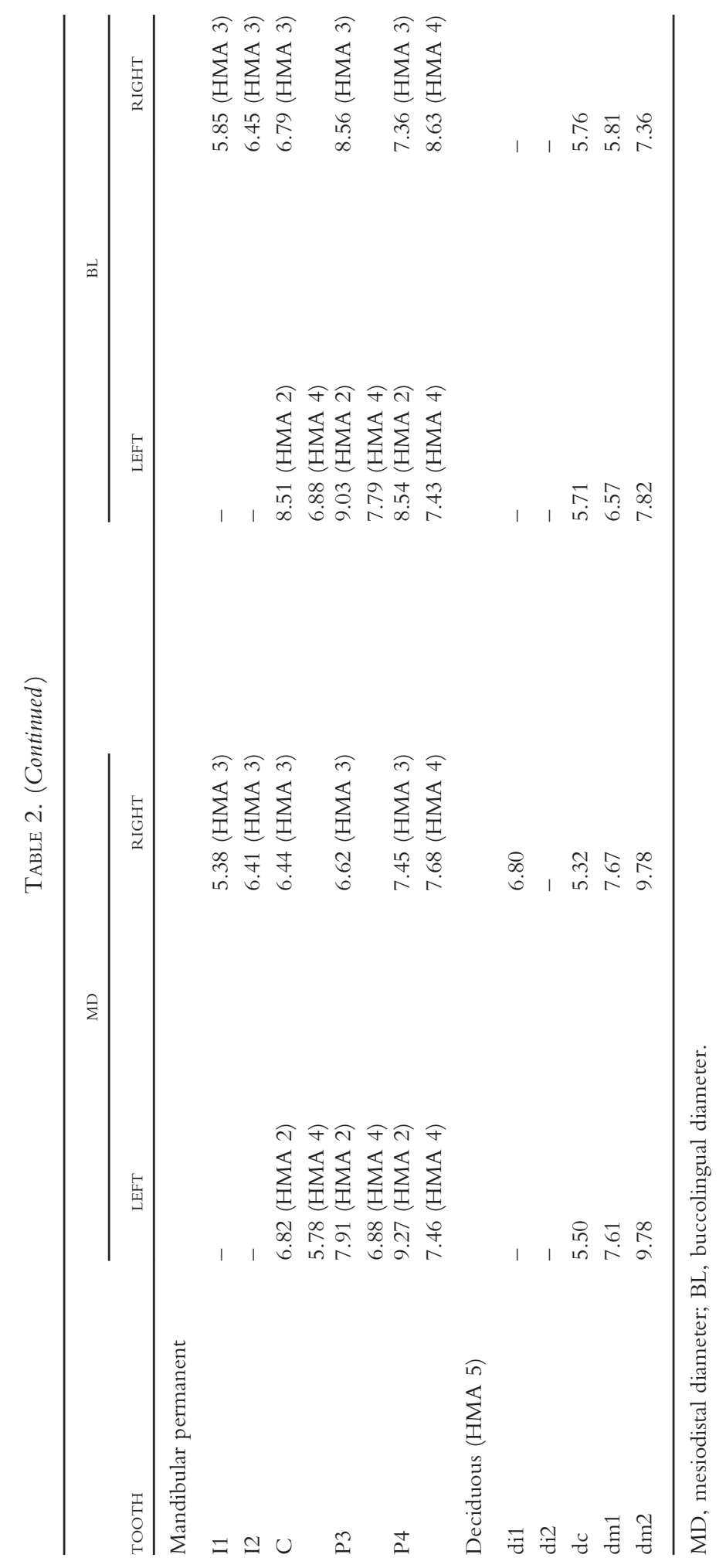




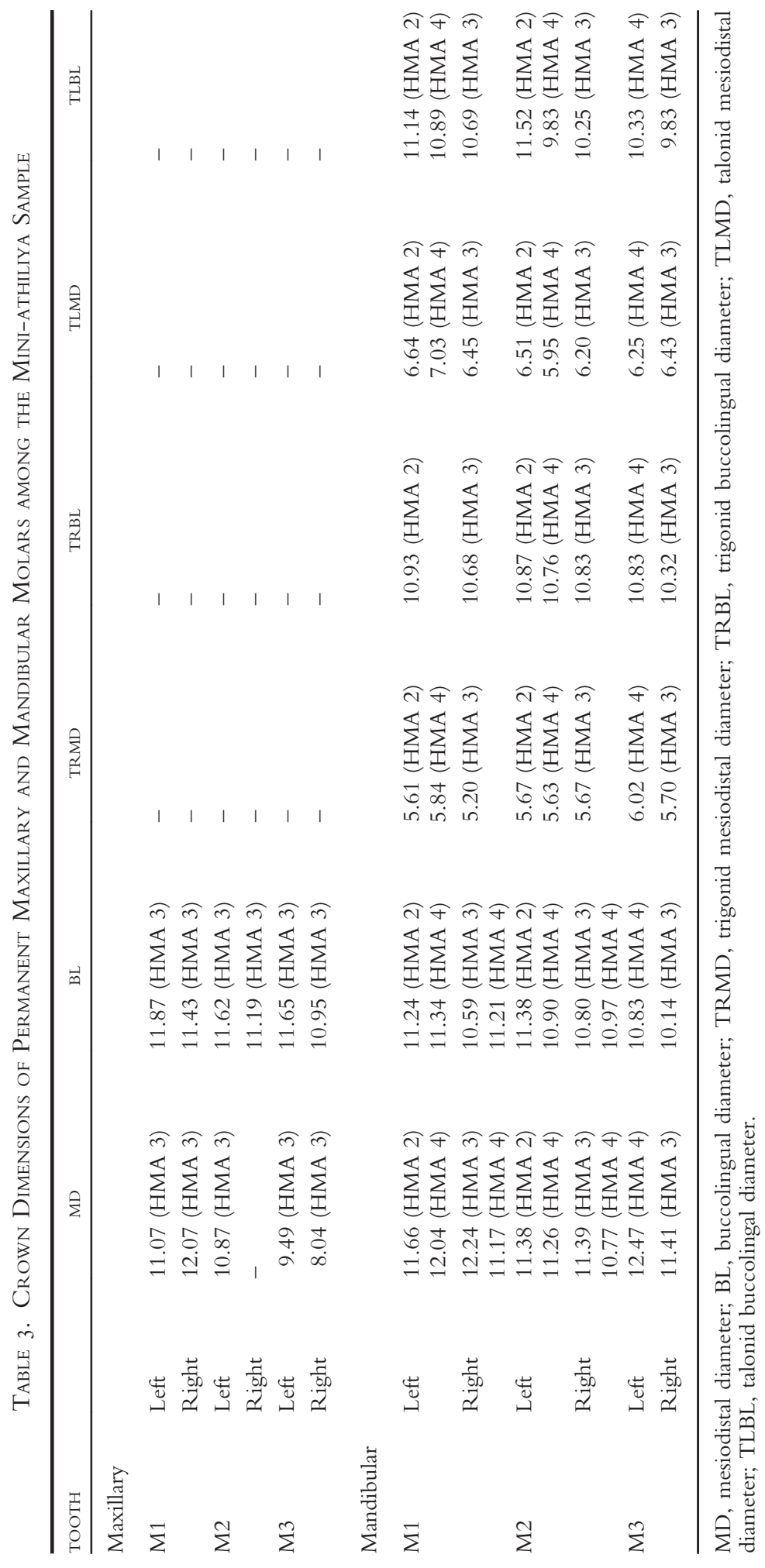




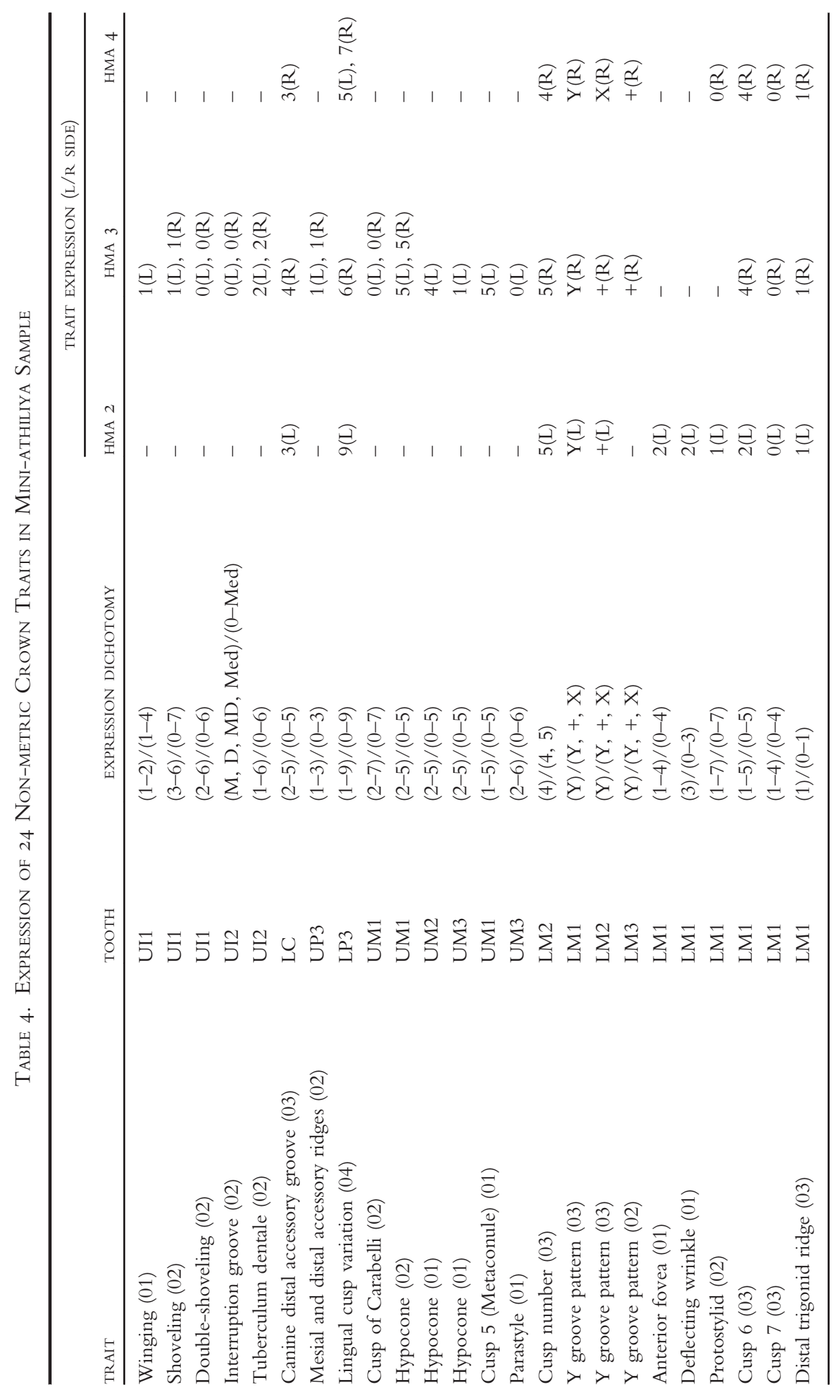


The sutural margins of cranial bones in this sample were obscured, damaged, or calcified. Hence, age assessment was based primarily on tooth eruption and wear. Tooth eruption is the primary method of age estimation for infants, children, adolescents, and young adults. Since population-specific chronology of tooth formation and eruption is rarely described for Sri Lankan populations, we used general standards to support our age estimates of Mini-athiliya people (Brothwell 1981; White et al. 2012).

Dental attrition is generally affected by age (Hojo 1954; Richards and Miller 1991; Tomenchuk and Mayhall 1979). Several detailed recording systems have been developed to score and measure occlusal attrition in order to determine the approximate age of an individual (Brothwell 1981; Scott 1979; Smith 1984). Brothwell's (1981) user-friendly dental attrition-based aging system is widely applied. Originally based on the Miles $(1963,2001)$ method of estimating age through macroscopic observation of wear on the occlusal surface of molar teeth, Brothwell's chart depicts the range of dentine exposure expected in permanent molars for four different age groups. It was devised for use in the study of prehistoric to early medieval British material, but since has been applied to archaeological populations worldwide (Constandse-Westermann 1997; Robbins et al. 2009; Watson 2008).

In the present study, we used the Brothwell (1981) system to estimate the age of subadult and adult individuals from Mini-athiliya. Figure 3 shows the Brothwell chart, representing a simple ordinal scoring system for classifying age in the following categories: 17-24 years, 25-34 years, 35-44 years, and 45 years or more. Each molar in the Mini-athiliya assemblage was classified independently according to these parameters. The classifications were conducted for all teeth on two different occasions, in order to allow intra-observer reproducibility of determinations.

Standard dental measurements were taken on the left and right mandibular and maxillary permanent and deciduous teeth of each individual using a digital vernier caliper (recorded to the nearest $0.01 \mathrm{~mm}$ ) (Fig. 4). The mesiodistal (MD) and buccolingual (BL) crown diameters were obtained according to Fujita's (1949) method. The MD and BL crown diameters of two crown components, the trigonid and talonid, of mandibular molars were also measured (Kondo et al. 1998; Yamada 1992) (Tables 2, 3).

The Arizona State University (ASU) dental anthropology system (Turner et al. 1991) was adopted for the classification of 24 non-metric dental traits (Table 4). The heritability of these traits is generally recognized to be moderately high despite environmental influences (Nichol 1989; Turner 1967, 1969). Accordingly, the expression of these traits can be regarded as a component of the genetic characteristics of the Mini-athiliya sample of people, aiding us in making some minimal yet useful inferences regarding their differences with and affinities to other regional populations.

\section{THE HUMAN REMAINS FROM MINI-ATHILIYA}

The human remains recovered from the rescue archaeology operation at Mini-athiliya posed several challenges for identification and analysis. As noted previously, they were highly fragmented and subjected to postmortem deformation due to recent haphazard mining activity. Since most skeletal elements were fragmented or missing, it was clear that the shell deposits containing mixed human bones from these burials had been completely damaged or sent to be crushed before the excavation team was able to salvage them.

The sorting process yielded fragmented human and animal remains encrusted with shells, calcium carbonate, and soil from the midden (Fig. 5). Table 1 summarizes the 


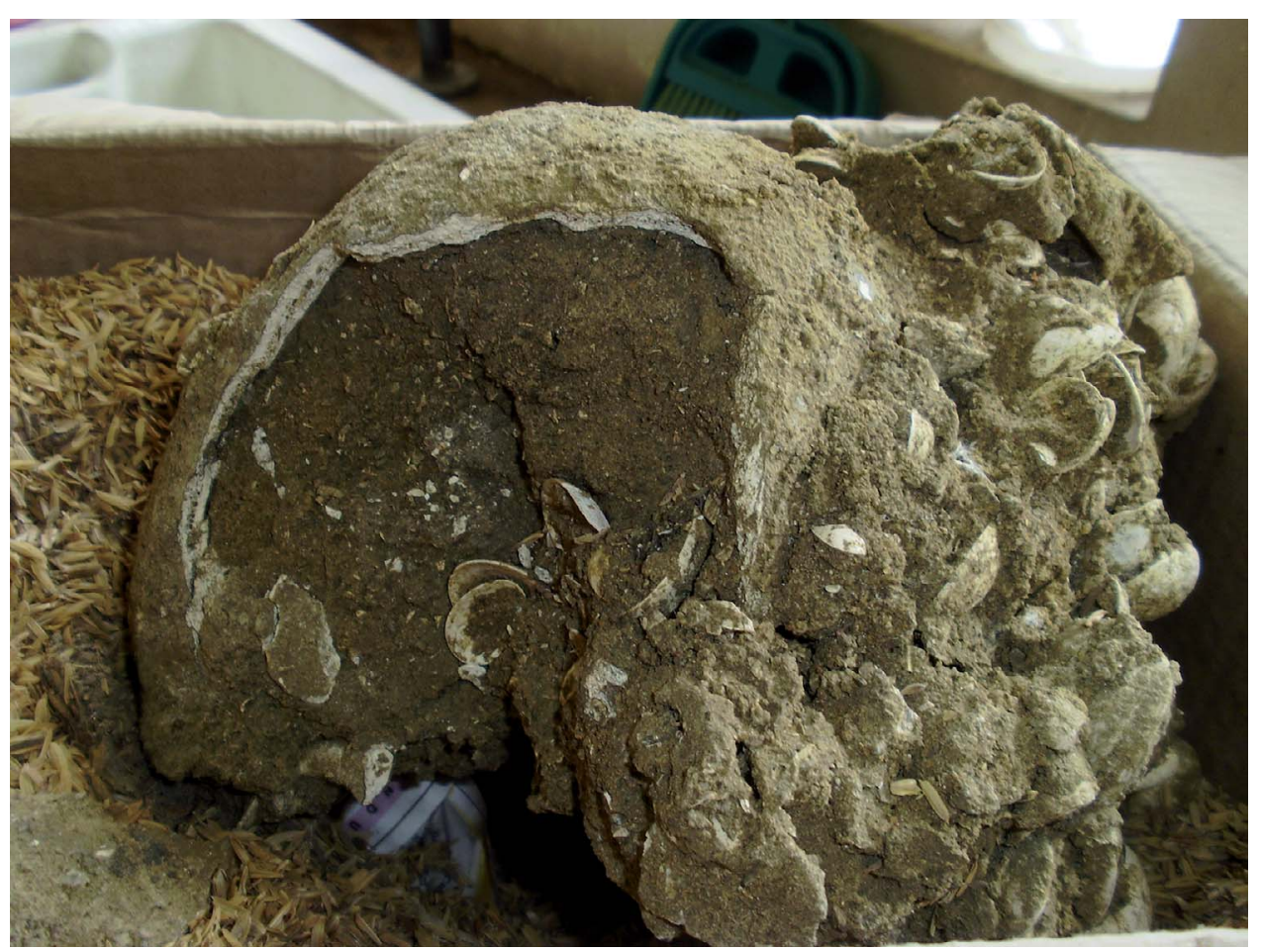

Fig. 5. Damaged calvarium encrusted with shells (HMA 3).

human remains identified from Mini-athiliya. Below, we provide descriptive accounts of the skeletal and dental elements assigned to HMA 1-6.

\section{$H M A 1$}

This individual was recognized based on an occipital bone that was articulated with a partial left parietal, left temporal, and frontal bone. The occipital bone had a welldeveloped occipital torus where the supreme and superior nuchal lines were clearly visible and joined medially. This feature was scored as OT 4, a relatively high robusticity grade according to the grades established by Lahr (1996). Fragmented and deteriorated cervical vertebrae and long bone fragments that likely belonged to this adult individual were also identified from the debris in associated bags of midden material from Pit 1.

\section{$H M A 2$}

A large clump of midden material from debris in Pit 2 yielded a distorted inferior part of a frontal bone with a relatively gracile supraorbital ridge. The nasal bones and the right zygomatic arch were attached to the frontal bone. Based on the grades for supraorbital ridges/torus in Lahr's (1996) classification system, we scored it as ST 1, described as a flat or very slightly projecting superciliary ridge and glabella. We were unable to obtain a reliable grade measure for the profile of the infra glabellar notch due to post-mortem 
damage to the region. Also in association within this clump of material was a fragmented left mandible with teeth (C, P3, P4, M1, M2) showing mild attrition. According to the Brothwell (1981) classification system, this mild pattern of wear is typical of an individual falling within the 17-25 year age group. Interestingly, P4 in HMA 2 showed five cusps (two buccal and three lingual) with a large talonid crown component. In addition, two roots (mesiobuccal and distolingual) in $\mathrm{P} 4$ were also evident in the CBCT images. We assess the age of this individual of unknown sex to be within the lower boundary of the above age range, at 17-22 years.

\section{HMA 3}

A calvarium and lower facial skeleton were recovered from Pit A (Fig. 6). The calvarium was comprised of a frontal bone, occipital bone, parietals, and temporals. Although the upper facial skeleton was missing, a portion of the maxilla and right mandible with teeth were found attached within the clay matrix (Fig. 6). The matching occlusal wear facets of the maxillary and mandibular teeth further validated that these elements and dentition belonged to the same individual. HMA 2 described above presented a left mandible, but we ascertained that these right and left mandibles belonged to two individuals based on differential dental eruption and wear.

The calvarium of HMA 3 had an estimated maximum cranial length of $180 \mathrm{~mm}$ and a maximum cranial breadth of $131 \mathrm{~mm}$. These measurements translate to a

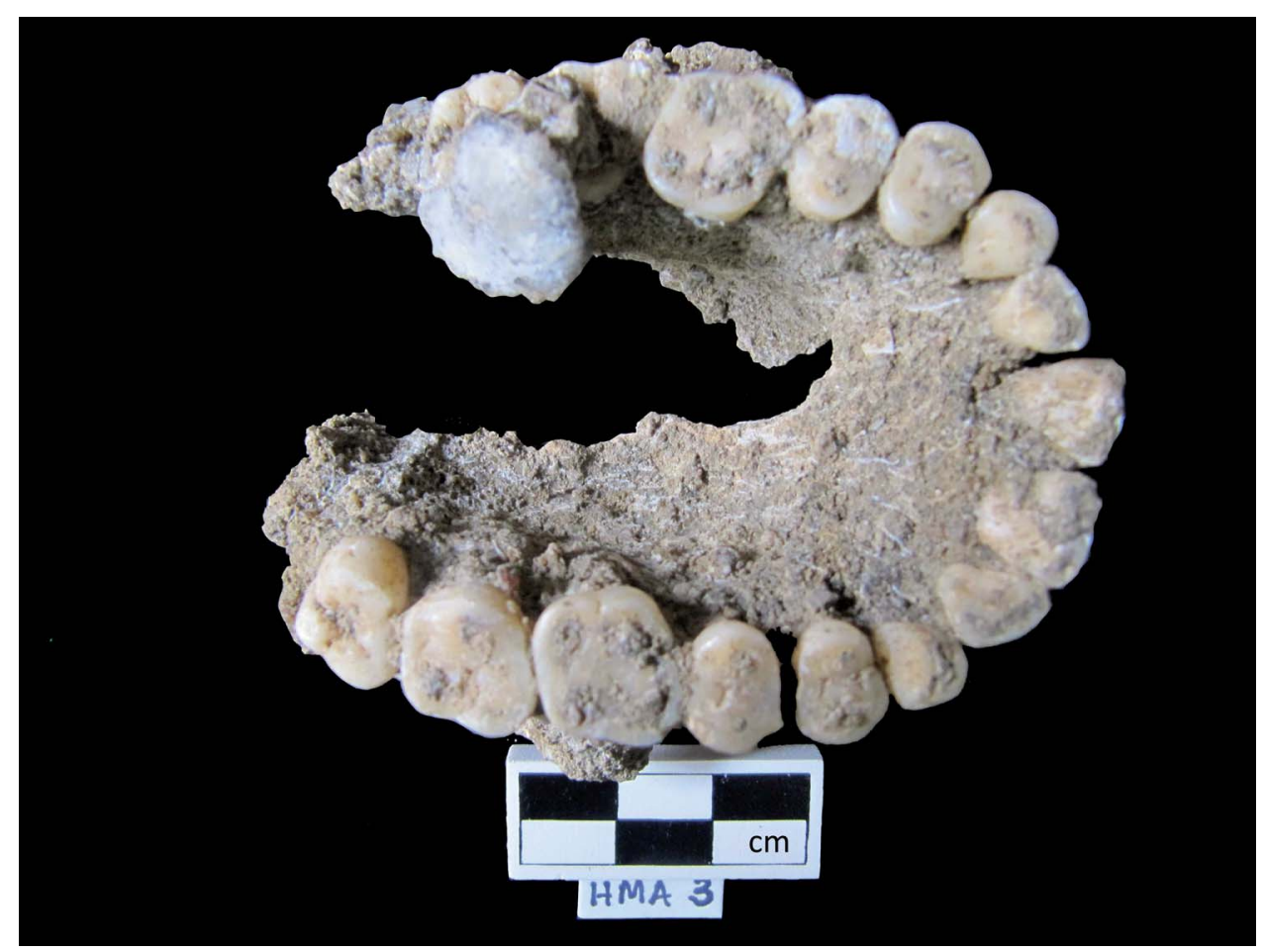

Fig. 6. Maxillary teeth showing moderate attrition (HMA 3). 
cranial index (CI) of 72.8 (CI = Maximum cranial breadth/maximum cranial length $\times 100)$. This measure falls in the range of dolichocrany $(x-74.99)$ representing a narrow and elongated cranium (Bass 2005). Moderate sagittal keeling, where the parietal bones are angled towards the sagittal suture yet lack a distinct ridge, was observed and scored as SK 2 according to the grades described by Lahr (1996). The maxilla and right mandible of HMA 3 had a total of 24 teeth. The teeth showed moderate attrition. Accordingly, we assigned this individual to a moderate wear pattern typical of an adult within the 25-35 year age group following Brothwell's (1981) classification of tooth wear. No periodontal disease or caries were observed in the teeth or associated bone. Based on the cranial and dental elements, we narrowed the age range for this relatively robust young adult to 25-30 years. While the absence of additional skeletal evidence hinders a firm assessment, we cautiously indicate that HMA 3 was possibly male.

\section{$H M A 4$}

Commingled bones from Pit 5 yielded a fragmented mandible with several posterior teeth showing moderate to severe attrition (Fig. 7). This wear pattern is typically associated with an individual aged 25-35 years based on Brothwell's classification. The tooth wear pattern diverged significantly from that of the mandibular dentition previously described and assigned to HMA 2 and HMA 3.

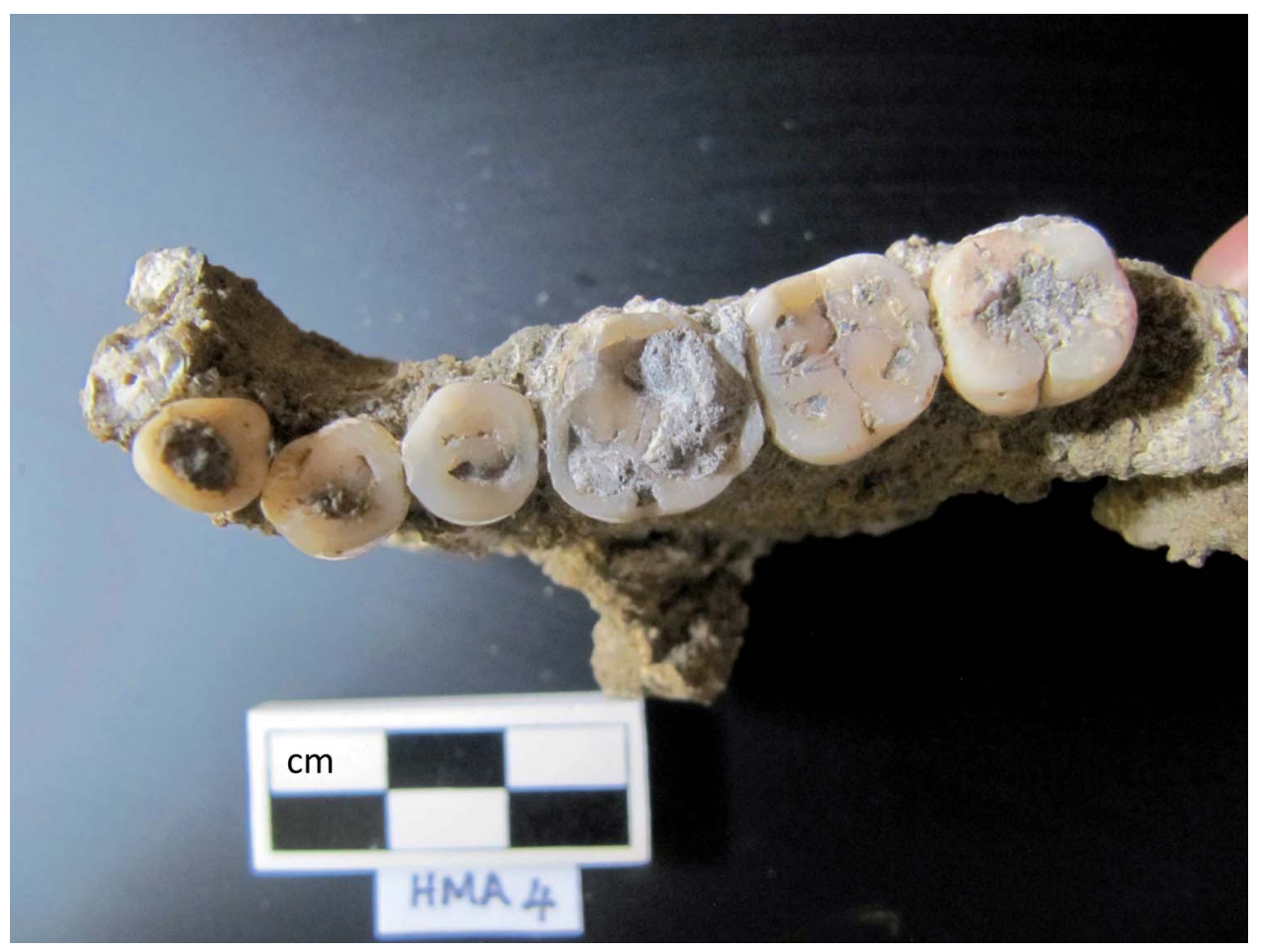

Fig. 7. Mandible fragment with teeth showing moderate to severe attrition (HMA 4). 
The hyoid, several cervical vertebrae, the superior part of the left scapula, fragments of the proximal left humerus, left clavicle, left radius, and the left femoral shaft were found in close association. The fragmentary nature and absence of diagnostic skeletal elements precluded the possibility of sexing this adult individual, which we estimate to be within the upper boundary of the given age range, at $30-35$ years.

\section{HMA 5}

Among the remains mixed with charcoal recovered from Pit 6 were some very fragile and fragmentary cranial bones and fragments of a mandible and maxilla, along with several deciduous teeth. The age of this individual (a child) was estimated based on the pattern of tooth eruption and the chronology of tooth developmental stages observed in the CBCT scans, which showed permanent teeth of different developmental stages within the maxilla and mandible. These scans allowed the accurate estimation of the age of this child to be $3-5$ years old.

\section{HMA 6}

This skeleton of a complete adult male was discovered intact during the systematic excavation at the Mini-athiliya site (H.N. Perera 2009). It was placed in a plaster cast with the surrounding matrix and was examined separately (Kulatilake et al. 2014). In this study we assessed the dentition for this individual. Eighteen maxillary and mandibular

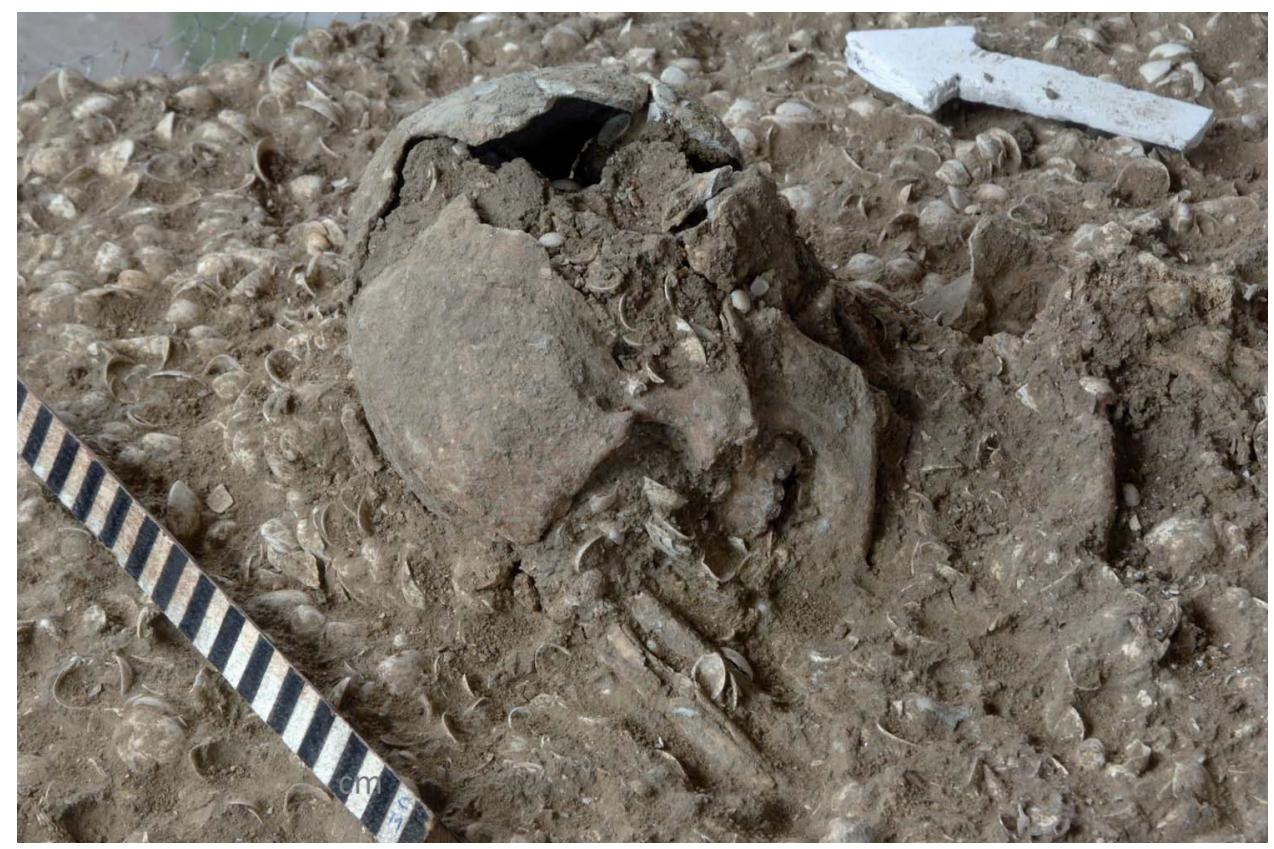

Fig. 8. In situ cranium and mandible (HMA 6). 


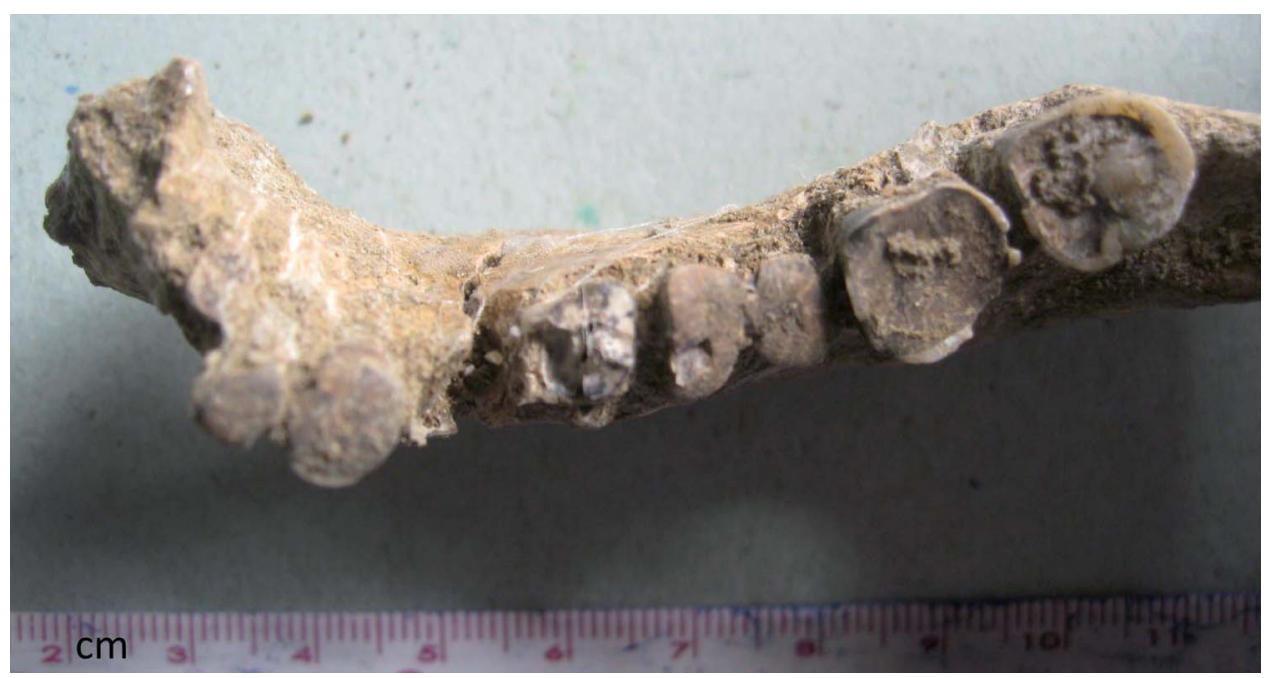

Fig. 9. Mandible fragment with teeth demonstrating severe attrition (HMA 6).

teeth were observed (Figs. 8, 9). All teeth showed severe attrition, with exposed secondary dentine or pulp cavity. Therefore, we were unable to observe or record metric and non-metric data on this individual. The type of severe wear pattern seen in HMA 6 is associated with an individual of about 45 years age according to the Brothwell (1981) chart of tooth wear. Moderate to severe alveolar bone loss adjacent to the anterior and posterior teeth in the maxilla and mandible indicating chronic periodontal disease was observed as well. Severe alveolar bone loss in HMA 6 may be partly related to that individual's advanced age and possibly to poor oral hygiene. Based on skeletal elements and dental attrition, we estimate the age of HMA 6 to have been $40-45$ years. This individual was therefore the oldest at time of death among the skeletal assemblage sample at Mini-athiliya.

\section{METRIC AND NON-METRIC DENTAL TRAITS OF MINI-ATHILIYA PEOPLE}

The data on tooth size among the Hungama Mini-athiliya (HMA) people are shown in Tables 2 and 3. The overall tooth size becomes progressively smaller from M1 to M3, with M1 being the largest tooth in both maxillary and mandibular dentition of the sample. When comparing the tooth size of individuals from the HMA sample with that of contemporary Sri Lankans, we found that the mean MD and BL diameters were larger amongst these early people than those for modern Sri Lankans (Chandrasekara and Nanayakkara 1999). This difference was more obvious in premolars and molars. In addition, among the HMA adult sample, the third maxillary and mandibular molars were fully erupted and comfortably seated within the arches, indicative of larger dental arch sizes.

The expressions in grades or classes of 24 non-metric dental traits in the HMA sample are shown in Table 4. The tuberculum dentale at the level of 1-6 in the maxillary I2, the canine distal accessory groove at the level of $2-5$ in the mandibular canine, mesial and distal accessory ridges at the levels of 1-3 in the maxillary P3, 
hypocone at the level of 2-5 in the maxillary M2, cusp 5 at the level of $1-5$ in the maxillary M1, and anterior fovea at the level of 1-4 in the mandibular M1 were observed in all available teeth studied. Winging, shoveling, double shoveling in maxillary I1 and a deflecting wrinkle and cusp 7 in mandibular M1 were not found in the dentition of the people in this sample.

\section{THE ARCHAEOLOGICAL ASSEMBLAGE FROM MINI-ATHILIYA}

The analysis of the faunal and lithic assemblages recovered from this salvage operation is ongoing. We provide below a short description of information from the preliminary reports compiled by the third and fourth authors of this article (H.J. Perera 2012; H.N. Perera 2009). A detailed analysis of the archaeological assemblage is outside the scope of this article. However, these initial bioarchaeological findings aid our exploration of the lifeways and affinities of the Mini-athiliya people.

The non-vertebrates from the site, including diverse shell species, are of prime importance in the examination of the Mini-athiliya people's subsistence pattern and diet (Fig. 10). A high reliance on shellfish is seen at the Mini-athiliya site, indicating that these people were aquatic foragers. The vast majority of shells belong to the edible saltwater clam species Meretrix meretrix. Also represented are other species such as Anadara sp., Marcia sp., Gafrarium tumidum, and Turbinella pyrum. These varieties would have been collected primarily from the inter-tidal zone near the Kalametiya lagoon and beach area, adjacent to the Mini-athiliya site. In addition to these salt water and brine varieties of shellfish, numerous terrestrial rainforest and freshwater mollusks were recovered during the excavation, including Paludomus sp. and Pila sp. Arboreal mollusks including Acavus superbus, Acavus phoenix, Acavus haemastoma, and Oligospira sp. were also identified in the sample. Acavus sp. are humidity-adapted snails that are no longer found in the vicinity of the site or within the dry and semi-arid zones of Sri Lanka (Hausdorf and Perera 2000). Their presence in Mini-athiliya suggest that the site may have been more humid in the past or that people collected these arboreal forms from wet zone habitats further inland.

A significant proportion of Acavus shells from Mini-athiliya are burnt. Some have circular perforations indicative of human modification, perhaps to extract the flesh. Strong parallels to this activity are noted from major prehistoric cave sites such as

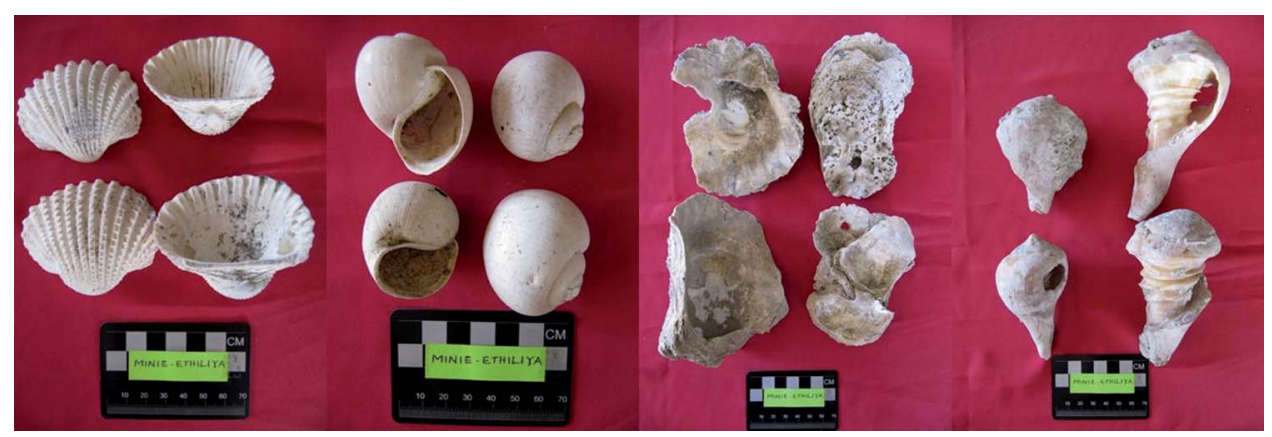

Fig. 10. Sample of shell species recovered from Mini-athiliya shell midden. 
Batadomba Lena, Fa Hien Lena, Kitulgala Beli Lena in Sri Lankan wet zones. Snails were consistently collected, processed, and consumed at these sites (Deraniyagala 1992; H.N. Perera 2010; Wijeyapala 1997). Of significance is the identification of three complete and several fragmented fish hooks fashioned primarily out of $A$. haemastoma shells (H.J. Perera 2016). The anthropogenic signature of the Mini-athiliya site is further established by the fact that gastropods such as mudflat shells (Cerithidea cingulata) and telescope shells (Telescopium sp.), which are found naturally in nearby estuarine locations, are notably less represented in the midden (H.N. Perera 2009).

A heavy concentration of shallow water, estuarine, and inshore habitat fish and marine fish bones recovered from the site demonstrate that the Mini-athiliya people relied on shallow water fishing. The shallow water fish remains identified within the midden include bones of catfish (Mystus sp.), barbs (Puntius sp.), grouper (Epinephelus sp.), emperor fish (Lethrinus sp.), barramundi (Lates sp.), and snapper (Lutjanus sp.). Marine fish represented in the sample include bones of trevally (Caranx sp.), mahimahi (Coryphaena hippurus), sharks (Carcharhinus sp.) and barracuda (Sphyraena sp.). Furthermore, the presence of large fish from shallow and deep waters suggests that the people of Mini-athiliya used various advanced fishing techniques. Shark teeth have been recovered from the ca. 13,000 B.P. level at Bellan-bandi Palassa and the ca. 20,000 B.P. level at Fa Hien cave, suggesting that these techniques may have been known since the terminal Pleistocene (H.N. Perera 2010).

Reptilian bones from Mini-athiliya represent hard shelled terrapins (Melanochelys sp.), soft shelled terrapins (Lyssemis sp.), crocodiles (Crocodylus porosus), and pythons (Python sp.) and other unidentified snake species. The terrapin bones are charred, suggesting that the flesh was extracted after roasting. The crocodile bones have cut marks and were crushed and charred, also indicative of human modification. The site of Bellan-bandi Palassa dated to the terminal Pleistocene (ca. 13,000 B.P.) has not yielded crocodile bones although it is located in a riverine environment (Deraniyagala and Kennedy 1972; H.N. Perera 2010). Only later populations of southern Sri Lanka, namely the aquatic foragers of Mini-athiliya, may have become adept at hunting these dangerous creatures (H.N. Perera 2009).

The mammalian faunal remains identified from Mini-athiliya include bones and teeth of wild water buffalo (Bubalus arnee), spotted deer (Axis axis), sambar deer (Rusa unicolor), mouse deer (Moschiola meminna), monkey species, mongoose (Herpestes sp.), porcupine (Hystrix indica), wild pig (Sus scrofa), elephant (Elephas maximus), pangolin (Manis crassicaudata), jackal (Canis aureus), giant squirrel (Ratufa macroura), palm cat (Paradoxurus sp.), cattle (Bos sp.), and dog (Canis familiaris). Several bones of jungle fowl (Gallus lafayetii) and other unidentified bird species were included in the faunal assemblage from Mini-athiliya (Fig. 11).

The presence of this diverse array of small and large animals at the site provide evidence that Mini-athiliya people relied upon hunting terrestrial animals as well as fishing and foraging for aquatic food sources. The cut marks and charring observed in the reptilian bones are also indicated on mammalian bones from the site. These bones do not show evidence of having been gnawed by scavengers, however. The remains of elephants in the sample were all of young animals. The majority of elephant bones found at Bellan-bandi Palassa are also from young individuals, suggesting that people strategically targeted manageable prey at both sites (H.N. Perera 2010). Of particular significance is the recovery and identification of a mandible and maxilla with premolars and/or molars and a complete metatarsal of a domesticated dog. Its 


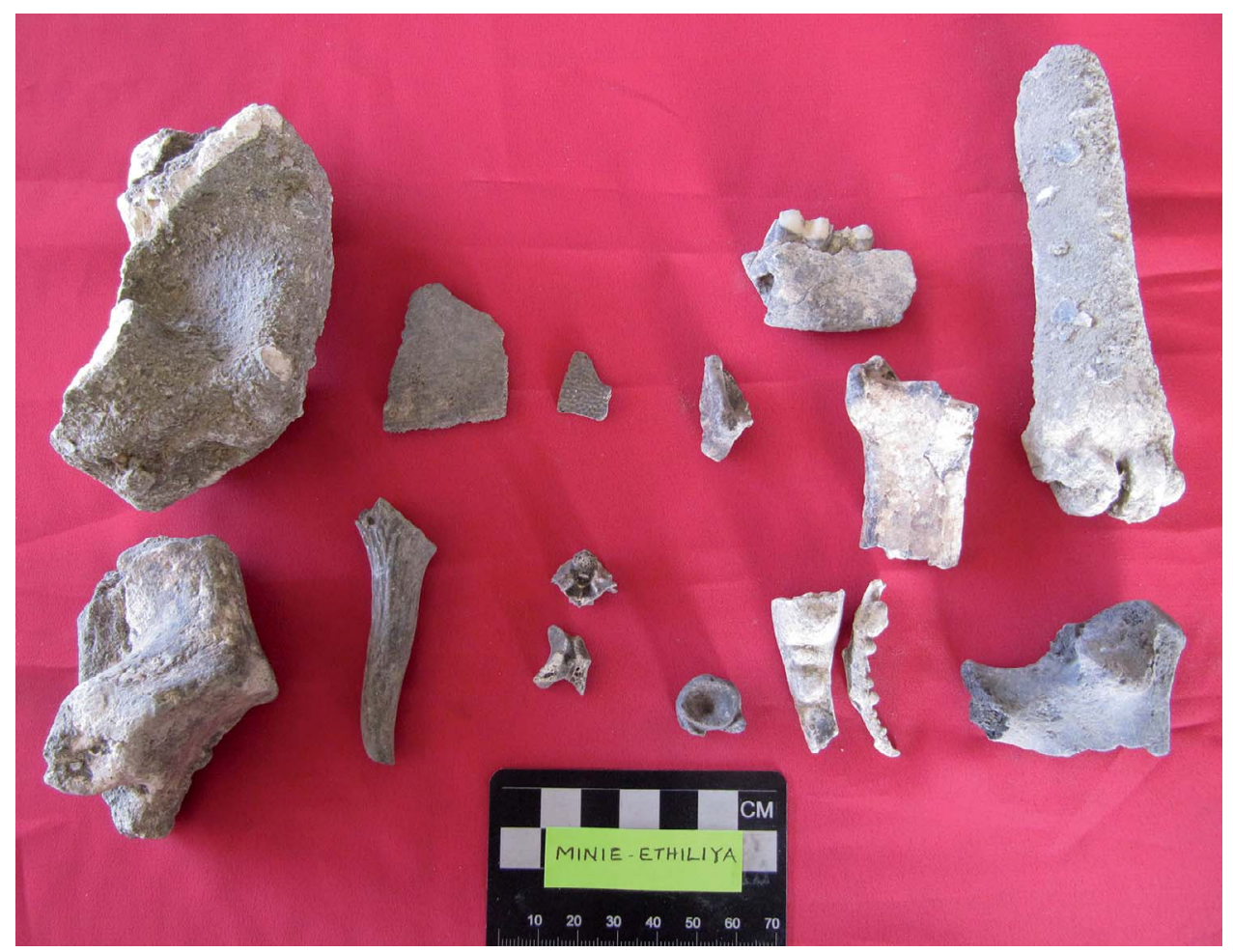

Fig. 11. Sample of faunal remains recovered at Mini-athiliya shell midden.

presence can be used to infer the existence of strategies that facilitated the successful hunting of larger prey. Also of importance is the discovery of several bones and teeth of domesticated cattle; these animals may have supplemented the diet of these people.

The lithic assemblage from Mini-athiliya presented a large number of stone artifacts and debris. These were recovered from the commingled remains salvaged from the site and from the systematic excavation that followed. We present here a preliminary summary to provide further context for the lifeways of the Mini-athiliya people represented in the present sample. Cores, complete flakes, flake fragments, and debitage have been recorded among the lithic assemblage from Mini-athiliya (Fig. 12). Chert and at least three types of quartz (clear, milky, and granular) are represented as raw materials for the stone tools, with the majority of tools being manufactured from clear quartz. A variety of formal implement types were present, including microliths, some of which had been backed or retouched, demonstrating use and wear. These demonstrate a continuation of the microlithic tool-making tradition of Sri Lanka up to the mid-Holocene.

Apart from the flaked lithic component of the assemblage, there were a few grinders and grinding stones. The smooth surfaces and traces of pigment on some of these grindstones indicate that they were used for grinding pigment such as red ochre. It is also possible that these grindstones were used for processing plant matter (H.N. Perera 2009). A few bone tools were collected from the Mini-athiliya excavation. These were 


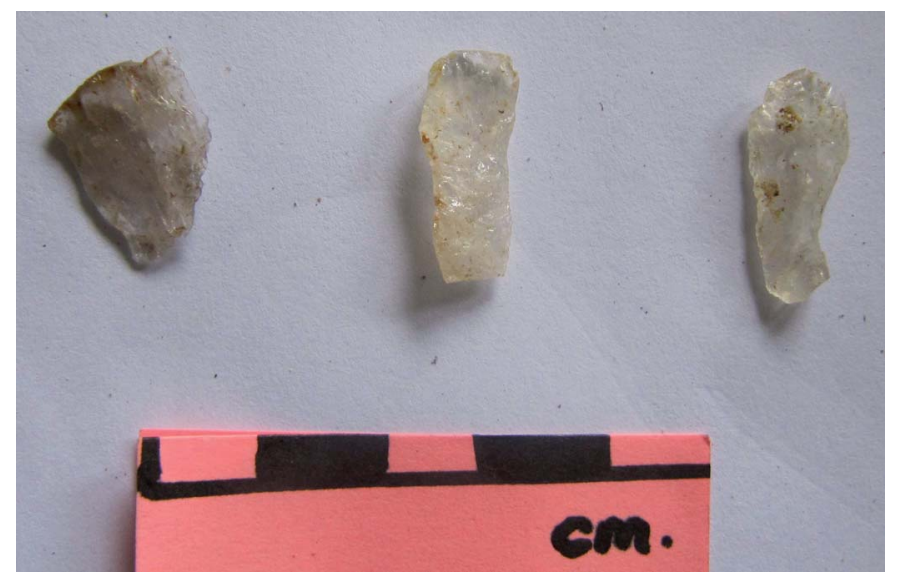

Fig. 12. Lithic debris (flakes) recovered from commingled remains at Mini-athiliya.

made from tough animal material such as horn and could be identified as tools by the polish, striations, and apparent wear damage through usage. The recorded bone implements include spatulas, single points, and plates. The bone tools were better preserved than other faunal material. Together with the presence of fish hooks made out of snail shells described above (H.J. Perera 2016), they provide tantalizing evidence of the versatility of the toolkit used by the Mini-athiliya people.

\section{DISCUSSION AND CONCLUSIONS}

Bioarchaeological studies that focus on early agriculturalists and large-scale civilizations far outweigh the number of studies conducted on contemporary hunter-gatherer or aquatic forager populations of South Asia. In this article, we describe the profiles of a sample of aquatic foragers comprised of six individuals identified from the Miniathiliya shell midden dated to ca. 3600 B.P. Most of the human remains recovered from Mini-athiliya shell midden were fragmented and poorly preserved. Given the incomplete nature of the cranial, postcranial, and dental remains, very little could be summarized regarding each individual's physiological attributes. Nevertheless, some of the skeletal and dental metric and non-metric observations offered an opportunity to assess the morphological characteristics of these people. Specifically, the analysis of dental non-metric traits could be used to make a few broad inferences on population distances and affinities.

We examined associated bioarchaeological remains to obtain background information on the sample of people from Mini-athiliya. Observations on the teeth of the Mini-athiliya people, when investigated alongside the faunal and lithic assemblage recovered in association, provided a lens for appreciating and inferring the dietary profile of the group. In addition, the faunal and lithic remains provide insights into the subsistence activities, technology, and lifeways of the Mini-athiliya people as aquatic foragers. We also tentatively infer cultural parallels between these and other contemporary populations from several locales in Sri Lanka. Due to the scarcity of data, interpretations and discussion of the skeletal and dental metric and non-metric data are 
limited. The assessments and conclusions we propose are informed by the limited number of observations we were able to make through analysis of a small sample of material salvaged from a disturbed context. However, the information gleaned from these skeletal and dental remains as well as the associated archaeological remains may shed some light on the demographics, morphology, affinities, and lifeways of these mid-Holocene people.

\section{Subsistence, Diet, and Dentition}

A large number of shells from different habitats (estuarine, marine and terrestrial) and charred animal bones were among the midden material found in association with the human remains from Mini-athiliya. The presence of abundant, selected, edible, disarticulated bivalve shells occurring in unsorted piles at the HMA site indicate that the people who occupied it some 3600 years ago subsisted on shellfish flesh and discarded the shells as kitchen refuse (Kulatilake et al. 2014). Since the faunal remains included elements from large and small mammals, reptiles, fish, and birds, it is apparent that the Mini-athiliya people exploited a variety of terrestrial and aquatic resources for their subsistence and were successful foragers and hunters. The associated microlithic tools and other stone tool implements, as well as the faunal tool assemblage, suggest that the people of Mini-athiliya skillfully manufactured tools and implements to obtain and process their food.

Caries-free teeth with minimal periodontal disease and moderate to severe attrition signify a cariostatic, yet highly abrasive, unprocessed diet among these mid-Holocene people. Among the Mini-athiliya skeletal sample, attrition as a result of tooth-to-tooth wear leading to wear facets was observed on all adult teeth (Hillson 2008). Low, moderate, severe and very severe attrition observed in HMA 2, HMA 3, HMA 4, and HMA 6 respectively, are likely related to age, sex, and diet. The lingual cusps of the upper molars and supporting buccal cusps of the lower molars wear more rapidly than the rest of the tooth, so that progressive wear converts the classic Curve of Monson first into a flat plane and then to a reversed curve (Hillson 1996:237-239). This wear pattern is observed in the dentition of the mature adult individuals from Mini-athiliya.

The cariostatic nature of marine diets is well documented (Kelley et al. 1991; Larsen et al. 1991). The associated archaeological assemblage and particularly the faunal remains indicate that the Mini-athiliya people relied heavily on a diet from estuarine and marine food sources. Diet is known as a dominant variable in the causation of caries (Hunter 1988). Although differential susceptibility to caries may be impacted by tooth wear, no caries were observed on the teeth of the Mini-athiliya people, not even among the individuals whose teeth presented low to moderate attrition. The fact that no caries were observed confirms that these aquatic foragers consumed a cariostatic diet low in starches and sugars. Furthermore, except in HMA 6, minimal alveolar bone loss, suggesting the absence of periodontal disease, was observed in the sample. This too may be attributed to a high fibrous and low carbohydrate diet. Further studies of the dentition, such as examining dental enamel hypoplasias, dental calculus, trace elements, and isotopes would be needed to establish additional details concerning the nutritional stresses and dietary patterns of the Mini-athiliya people.

Jaw and anterior tooth size are linked to the size of ingested food particles, while the sizes of post canines depend on the deformation and external physical characterisitcs of food particles (Lucas 2004). Therefore, the larger teeth and facial skeletal framework 
observed in these mid-Holocene people may be attributed to their diet of tough unprocessed food and the higher masticatory forces involved in chewing. They had not undergone the microevolutionary changes associated with sedentism and a dietary shift toward the consumption of more processed food.

The two-rooted mandibular premolar observed in one of the individuals can be considered an ancestral trait in the continuum of the evolution of dental morphology among humans. One trend in the variation in hominin mandibular premolar root form has been described as a morphocline based on the presumed ancestral condition of mandibular $\mathrm{P} 3$ and $\mathrm{P} 4$ root systems, leading towards root reduction from a two-rooted to a one-rooted mandibular P3 and P4. This trend has been seen among Homo erectus and Homo sapiens populations (Scott and Symons 1982; Wood et al. 1988). Two-rooted mandibular premolars are rarely found in modern peoples, yet when they are found, it is usually amongst South Asians (Goh 1957; Kraus et al. 1969; Shapira and Delivanis 1982).

\section{Bio-Cultural Similarities of the Mid-Holocene Aquatic Foragers of Sri Lanka}

In southern Sri Lanka, numerous shell deposits and midden sites have been identified by geologists and archaeologists (Deraniyagala 1992; Katupotha 1995). Some of these sites have yielded human remains with dates for occupation recorded within the midHolocene. Anthropogenic shell middens sharing several features in southern Sri Lanka have been recognized as a class of archaeological sites and have been described as a cultural complex based on their common attributes (Deraniyagala 1992; Kulatilake 2016; Somadeva and Ranasinghe 2006). The primary exploitation of aquatic resources along with other inland resources, microlithic and later stone tool types, and the mortuary practice of flexed burials are among some of the cultural features shared by the people who lived within this temporal and spatial context.

The cultural similarities between shell midden populations from Mini-athiliya, Pallemalala, and Godawaya, located in close proximity to each other and presumed to be contemporaneous, indicate that these local groups specialized in exploiting resources in different ecosystems. The Godawaya people would have had direct access to the open ocean and show elevated levels of marine resource exploitation (Karunaratne et al. 2016), while the Mini-athiliya and Pallemalala sites are located further inland and faunal evidence from these two sites indicate intensified exploitation of shell species (Kulatilake et al. 2014; Somadeva and Ranasinghe 2006). High levels of dental attrition observed among individuals belonging to this cultural complex suggests an abrasive diet typical of people consuming relatively unprocessed food containing grit from marine and estuarine environments (Kulatilake et al. 2014; Ranaweera 2002; Wahl n.d.).

Striking similarities in the mortuary practices among these groups have also been observed. The complete burial recovered in situ from Mini-athiliya was in a tightly flexed fetal position with the head placed to the north (Kulatilake et al. 2014). Although the Godawaya 2007 excavation project report is yet to be published, findings reported in the popular media included photographs of a flexed burial (e.g., Amazing Lanka 2017). ${ }^{1}$ This mortuary pattern is also observed at the Pallemalala site, where most burials were in flexed positions with the skulls placed to the north (Somadeva and Ranasinghe 2006). In addition, the high degree of skeletal robusticity and/or long, narrow cranial shape observed among the mid-Holocene people of Mini-athiliya 
(Kulatilake et al. 2014), Pallemalala (Kulatilake 2012; Ranaweera 2002), and Godawaya (Wahl n.d.) suggest that these groups living in possible temporal and spatial proximity may have shared biological links as well. We acknowledge that these inferences need to be tested further before firm conclusions can be made. A serious limitation faced is the paucity of published data from shell midden sites in southern Sri Lanka as well as the absence of secure, calibrated radiocarbon dates from sites such as Pallemalala and Godawaya.

The comparison of non-metric dental features has been valuable in assessing affinities among human populations, since teeth represent intra-population homogeneity and inter-population variation (Scott and Turner 1997). A biological continuum has been proposed for the early inhabitants of Sri Lanka (popularly known as the Balangoda people) in relationship to the indigenous Vedda people of the island (Deraniyagala 1958, 1992; Hawkey and Kennedy 1993; Kennedy 2000). Dental anthropological analyses have shown that the traits shared by the early Balangoda people and the indigenous Vedda distinguish these groups from later arrivals of the Sinhala and Tamil peoples to Sri Lanka (Hawkey 2002). To understand these affinities and distances, the South Asian dental pattern is referred to as the "Indodont" pattern based on the internal homogeneity in several dental traits among South Asian groups, including Sri Lankan ancient and recent people (Hawkey 1999, 2002).

The Indodont pattern is characterized relative to other world populations' dental trait averages as having high frequencies of the following traits: a hypocone in maxillary M2, one-rooted maxillary P3, lingual cusp variation in mandibular P4, and four cusps in mandibular M2. In addition, the Indodont pattern presents average frequencies in the following traits: shoveling in maxillary I1, presence of an interruption groove in maxillary I2, presence of a distal accessory ridge in the permanent maxillary canine, cusp of Carabelli in maxillary M1, the Y-groove pattern in mandibular M2, cusp 6 and cusp 7 in mandibular M1, the deflecting wrinkle in mandibular M1, and protostylid in mandibular M1. The absence or low frequencies of winging and double shovelling in maxillary I1 and enamel extension in maxillary M1 also characterize the Indodont pattern (Hawkey 1998). The Mini-athiliya sample does not show the high prevalence of winging, shoveling, and double-shoveling in maxillary I1 commonly found among Sinodonts, people of East Asian descent. However, as expected, a high prevalence of a hypocone in maxillary M2 and low prevalence of Carabelli's cusp in maxillary M1 and winging in maxillary I1 situates the (admittedly small) Mini-athiliya sample within the Indodont pattern of non-metric traits associated with South Asians.

A common trend in modern human cranial evolution is gracilization, with the reduction of robusticity and size (Lahr 1996). Higher cranial lengths are correlated more with robusticity than are higher cranial breadths (Lahr 1996:253). Dolichocrany, which refers to a relatively long and narrow cranial shape, is reported among the sample of Mini-athiliya people and the Pallemalala people (Kulatilake 2012). Furthermore, Kennedy (2000:237) describes the Bellan-bandi Palassa crania from the early to midHolocene time as robust and dolichocranic, providing an opportunity to infer that the mid-Holocene people associated with the midden complexes of Sri Lanka were relatively robust individuals overall. With regards to non-metric cranial traits, the adults of this assemblage show a high degree of musculoskeletal robusticity as observed in their cranial elements, reminiscent of the robusticity observed among other modern humans from the mid-Holocene in Sri Lanka and other South Asian contexts (Kennedy 2000; 
Kulatilake 2000). The extremely small sample size from Mini-athiliya and other sites in the region poses a problem in presenting firm conclusions in these assessments, however.

Peiris and colleagues (2003) reported that the crown area values of the mandibular molars and the maxillary second molar of the Pallemalala people were larger than among contemporary populations of Sri Lanka. The results of the present study on the Mini-athiliya people's dentition are in agreement with the observations of the Pallemalala sample. Larger molar sizes, along with the absence of crowding in the dental arches as shown in this study, could be associated with a greater degree of robusticity, a shared gene pool, and similar diets among these contemporaneous people from the mid-Holocene.

The estimated age at death for the skeletal assemblage from Mini-athiliya is 5-45 years. The age range for the skeletal assemblage recovered from Pallemalala was between 20 and 45+ years (Ranaweera 2002; Somadeva and Ranasinghe 2006). The three skeletons recovered from Godawaya included a juvenile, young adult, and mature adult (Wahl n.d.). The small and fragmentary samples from Mini-athiliya and other sites in the region preclude an analysis of the lifespan of these people, but death prior to completing the fifth decade of life could be attributed to trauma associated with a harsh lifestyle (Kennedy 2000; Lukacs 1990). As indicated previously, more evidence and the ability to apply refined techniques are required to test and verify the observations and inferences we make here.

\section{Shell Deposits as Sources of Bioarchaeological Information}

The archaeological significance of several coastal shell middens in Sri Lanka is undisputed. Since shell mounds are visually obvious in the landscape, they are often quarried for lime to be used in construction and chicken-feed. Both Pallemalala and Mini-athiliya archaeological sites were encountered accidentally during commercial shell mining at those locales (Kulatilake et al. 2014; Somadeva and Ranasinghe 2006). The Godawaya site area had been quarried for gravel and granite prior to 2007 (Karunaratne et al. 2016).

Recent large scale commercial exploitation of shell middens as coastal economic resources challenges the protection of archaeological assemblages. Ancient peoples in these areas consumed vast quantities of shellfish and discarded the shells along with culturally modified faunal remains and tool assemblages; they even buried their dead within the midden deposits. Although naturally occurring shell beds or shell deposits may be suitable for exploitation (using responsible techniques) as a commercial resource, the same cannot be said of shell middens exhibiting an archaeological signature. Once excavated by local miners, both the naturally occurring shell deposits and middens primarily comprised of shells (but occasionally containing human bones, teeth, stone tools, and other archaeological evidence) would be transported for crushing at local mills. Indiscriminate shell mining in the region has unfortunately contributed to the loss of valuable bioarchaeological evidence, as seen at the Miniathiliya site. The damage accruing to archaeological resources due to unwitting commercial exploitation of shell middens was highlighted during the salvage archaeology operation at Mini-athiliya, which was only able to recover highly fragmented remains of several individuals from the mined midden debris.

Here we have examined a skeletal sample representing a small-scale, aquatic forager society of South Asia. This study diverges from the apparent bias in the region toward 
focusing on agriculturalists, large scale settlements, and civilizations. The major limitation we faced was that these skeletal remains were very damaged and fragmented. Although the sample size of 72 teeth was extremely small, it represented approximately 40 percent of the total number of teeth possible for five adults and one child. A larger sample would have allowed for a greater degree of reliability in the inferences we proposed. Until further skeletal and dental evidence is available and testing can be accomplished, we nonetheless maintain that the present study contributes toward understanding the biological anthropology of the Mini-athiliya people and midHolocene aquatic foragers of the region in general.

This study presented archaeological and anthropological data from a highly disturbed context and attempted to associate the findings with a broader cultural assemblage. This research provided an opportunity to acknowledge and assess the seldom studied mid-Holocene subsistence pattern of aquatic foraging/hunting and gathering in South Asia and the biological anthropology of the people whose lifeways were based upon it. Further studies on the finds from Mini-athiliya and other midden sites, as well as systematic surveys and scientifically executed excavations, would enhance our knowledge of the mid-Holocene bioarchaeological record of South Asia.

\section{ACKNOWLEDGMENTS}

The salvage archaeology operation at Mini-athiliya was funded by the National Department of Archaeology, Sri Lanka. Partial funding for post-excavation analyses was provided by Mount Royal University. We acknowledge the assistance and contributions of Senarath Dissanayake, Director General, Sri Lanka Department of Archaeology. We are grateful to Siran U. Deraniyagala for his valuable insights. We thank the excavation team and members of the Excavation Branch of the Sri Lanka Department of Archaeology and volunteer students from the University of Sri Jayewardenepura, Michael Allan, Aruna Jayaweera, Ruwan Jayasinghe, Kapila Arambawatta, Sudevi Ranasinghe, and Priyantha Karunaratne. We thank the anonymous reviewers from Asian Perspectives for providing useful feedback and suggestions for improvements.

\section{NOTES}

1. 2017 Godawaya Prehistoric Site (webpage) at Amazing Lanka (website), URL: amazinglanka.com/ wp/godawaya/

\section{REFERENCES CITED}

Bass, William M.

2005 Human Osteology: A Laboratory and Field Manual. $5^{\text {th }}$ ed. Springfield: Missouri Archaeological Society.

Biagi, PaOlo

2013 The shell middens of Las Bela coast and the Indus delta (Arabian Sea, Pakistan). Arabian Archaeology and Epigraphy 24(1):9-14.

BRothWELl, D. R.

1981 Digging up Bones: The Excavation, Treatment, and Study of Human Skeletal Remains. London: British Museum (Natural History).

Buikstra, J. E., and D. H. Ubelaker, eds.

1994 Standards for Data Collection from Human Skeletal Remains. Arkansas Archaeological Survey Research Series No. 44. Fayetteville, AR: Arkansas Archaeological Survey. 
Ceci, LynN

1984 Shell midden deposits as coastal resources. World Archaeology 16(1):62-74.

Chandrasekara, M., and C. D. Nanayakkara

1999 Crown dimensions of the permanent teeth in Sri Lankans. Sri Lanka Dental Journal 28:15-18.

Constandse-Westermann, T. S.

1997 Age estimation by dental attrition in an independently controlled early 19th century sample from Zwolle, The Netherlands. Human Evolution 12(4):269-285.

Deraniyagala, P.E.P.

1958 An open-air habitation site of Homo sapiens balangodensis. Spolia Zeylanica 28(2):223-261.

Deraniyagala, Siran U.

1992 The Prehistory of Sri Lanka: An Ecological Perspective, vol. 1 \& 2. Colombo: Department of Archaeological Survey.

Deraniyagala, Siran U., and Kenneth A. R. Kennedy

1972 Bellan-Bandi Palassa: A Mesolithic burial site in Ceylon. Ancient Ceylon 2:18-47.

FujiTA, T.

1949 On the standard of the measurement of teeth. Journal of the Anthropological Society of Nippon 61:27-32 (in Japanese).

GoH, S. W.

1957 Variations in the morphology of mandibular premolar roots. British Dental Journal 102:311-314.

Hawkey, Diane E.

1998 Out of Asia: Dental Evidence for Affinities and Microevolution of Early Populations from India/Sri Lanka. Ph.D. Thesis. Department of Anthropology, Arizona State University.

1999 The Indodont dental pattern of prehistoric South Asia and early world affinities. American Journal of Physical Anthropology S28:146-147.

2002 The peopling of South Asia: Evidence for affinities and microevolution of prehistoric populations of India and Sri Lanka. Spolia Zeylanica 39:1-300.

Hawkey, Diane E., and Kenneth A. R. Kennedy

1993 Biological affinities of prehistoric Sri Lankans: A comparative study of dental morphology. American Journal of Physical Anthropology S16:105.

Hausdorf, Bernhard, and Kalika K. Perera

2000 Revision of the genus Acavus from Sri Lanka (Gastropoda: Acavidae). Journal of Molluscan Studies 66:217-231.

Hillson, S. W.

1996 Dental Anthropology. Cambridge: Cambridge University Press.

2008 Dental pathology, in Biological Anthropology of the Human Skeleton: 301-340, ed. M. A. Katzenberg and S. R. Saunders. New York: Wiley-Liss.

Hojo, M.

1954 On the pattern of the dental abrasion. Okajimas Folia Anatomica Japonica 26:11-30.

Hunter, P. B.

1988 Risk factors in dental caries. International Dental Journal 38(4):211-217.

Kanthilatha, W.S.P.Y.N., S. G. Yasawardene, G. Adikari, W. E. Boyd, and M. M. Pathmalal 2012 Re-visiting the Bellan-Bandi Palassa human remains of the Mesolithic period, Sri Lanka. Man and Environment 37(2):7-17.

Karunaratne, Priyantha, Samanti Kulatilake, H. Nimal Perera, H. Jude Perera, Piyawathi Vidanapathirana, Sampath Garusinghe, Hans Harmsen, K.M.G. Jinaka, Ruwan Dissanayake

D. R. Abeykoon, and Ratnasiri Pieris

2016 Excavation at Godawaya middle Holocene habitation site, summer 2014: Preliminary Report. Sri Lanka: Postgraduate Institute of Archaeology.

KATUPOTHA, JiNADASA

1988 Hiroshima University radiocarbon dates: West and south coasts of Sri Lanka. Radiocarbon 30 (3):341-346.

1995 Evolution and geological significance of Holocene emerged shell beds on the southern coastal zone of Sri Lanka. Journal of Coastal Research 11(4):1042-1061. 
Kelley, Marc A., Dianne R. Levesque, and Eric Weidl

1991 Contrasting patterns of dental disease in five early northern Chilean groups, in Advances in Dental Anthropology: 203-213, ed. M. A. Kelley and C. S. Larsen. New York: Wiley Liss.

Kennedy, Kenneth A. R.

1965 Human skeletal material from Ceylon, with an analysis of the island's prehistoric and contemporary populations. Bulletin of the British Museum of Natural History (Geology) 11:135-213.

1975 The Physical Anthropology of the Megalith-Builders of South India and Sri Lanka. Canberra: Australian National University Press.

1976 Biological anthropology of prehistoric populations in South Asia: A survey of current research efforts, in Ecological Backgrounds of South Asian Prehistory: 166-178, ed. Kenneth A. R. Kennedy and G. L. Possehl. New York: Cornell University.

2000 God-Apes and Fossil Men: Paleoanthropology in South Asia. Ann Arbor: The University of Michigan Press.

Kennedy, Kenneth A. R., and A. A. Elgart

1998 Hominid Remains. An Up-date. South Asia: India and Sri Lanka. Supplement to Anthropologie et Préhistoire No. 8, ed. R. Orban and P. Semal. Brussels: Royal Belgian Institute of Natural Sciences.

Kondo, S., T. Funatsu, S. Amino, R. Sasa, and E. Wakatsuki

1998 An odontometrical analysis of the mandibular molariform teeth in the Japanese males. Pediatric Dental Journal 8:73-77.

Kraus, B. S., R. E. Jordan, and L. Abrams

1969 Dental Anatomy and Occlusion. Baltimore: Williams and Wilkins Co.

Kulatilake, Samanti

2000 Cranial Diversity and the Evolutionary History of South Asians. Ph.D. Thesis. Department of Biological Anthropology, University of Cambridge.

2009 Early occupation of coastal Sri Lanka, in Asian Perspectives on Human Evolution: 207-214, ed. A. R. Sankhyan. New Delhi: Serials.

2012 A comparative study of human cranial and dental remains from Mini-athiliya and Pallemalala, in Punkalasa: Research Papers of the National Archaeology Symposium: 151-163. Colombo: Department of Archaeology.

2016 The peopling of Sri Lanka from prehistoric through historic times: Biological and archaeological evidence, in A Companion to South Asia in the Past: 426-436, ed. G. Robbins-Schug and S. Walimbe. New Jersey: Wiley-Blackwell.

Kulatilake, Samanti, Nimal Perera, Siran U. Deraniyagala, and Jude Perera

2014 The discovery and excavation of a human burial from the Mini-athiliya shell midden in Southern Sri Lanka. Ancient Asia 5(3):1-8.

LaHr, Marta M.

1996 The Evolution of Modern Human Diversity. Cambridge: Cambridge University Press.

Larsen, C. S., R. Shavit, and M. C. Griffin

1991 Dental caries evidence for dietary change: An archaeological context, in Advances in Dental Anthropology: 179-202, ed. M. A. Kelley and C. S. Larsen. New York: Wiley Liss.

LuCAS, P. W.

2004 Dental Functional Morphology: How Teeth Work. Cambridge: Cambridge University Press.

Lukacs, J. R.

1984 The People of South Asia: The Biological Anthropology of India, Pakistan and Nepal. New York: Plenum Press.

1990 On hunter-gatherers and their neighbors in prehistoric India: Contact and Pathology. Current Anthropology 31(2):183-186.

Miles, A.E.W.

1963 The dentition in the assessment of individual age in skeletal material, in Dental Anthropology: 191-209, ed. D. R. Brothwell. London: Pergamon Press.

2001 The Miles method of assessing age from tooth wear revisited. Journal of Archaeological Science 28:973-982.

NiCHOL, C. R.

1989 Complex segregation analysis of dental morphological variants. American Journal of Physical Anthropology 78(1):37-59. 
ORTON, J.

2009 Rescue excavations at Diaz Street Midden, Saldanha Bay, South Africa. Archaeological Research in Africa 44(1):107-120.

Peiris, H.R.D., R. Somadeva, I. Kageyama, and C. D. Nanayakkara

2003 An odontometric study of the permanent molars of a prehistoric population who lived in a coastal region of Sri Lanka - Pallemalala. Anthropological Science 111(1):46.

Perera, H. Jude

2012 Hungama Mini-athiliya shell midden. Punkalasa: Research Papers of the National Archaeology Symposium, vol. 2: 287-291. Colombo: Department of Archaeology (in Sinhala).

2016 Earliest Fish hooks from Sri Lanka identified from the Prehistoric Mini-athiliya shell midden deposit. Ancient Ceylon 25:157-168 (in Sinhala).

Perera, H. Nimal

2009 Mini-athiliya Excavation Report. Colombo: Department of Archaeology.

2010 Prehistoric Sri Lanka: Late Pleistocene Rock shelters and an Open Air Site. British Archaeological Reports 2142. Oxford: Archaeopress.

Premathilake, R.

2006 Relationship of environmental changes in Central Sri Lanka to possible prehistoric land-use and climate changes. Palaeogeography, Palaeoclimatology, Palaeoecology 240(3):468-496.

RANAWEERA, R.M.S.L.

2002 A Study of Human Skeletal Remains from Pallemalala Shell-Midden in Southern Sri Lanka. B.Sc. Thesis. Department of Anatomy, University of Sri Jayewardenepura, Nugegoda.

Richards, M. B., AND S. Miller

1991 Relationships between age and dental attrition in Australian Aboriginals. American Journal of Physical Anthropology 84(2):159-164.

Robbins, G., V. Mushrif Tripathy, V. N. Misra, R. K. Mohanty, V. S. Shinde, Kelsey M. Gray, and

Malcolm D. Schug

2009 Ancient skeletal evidence for leprosy in India (2000 B.c.). PLoS ONE 4(5):e5669.

ScOTT, E.C.

1979 Dental wear scoring technique. American Journal of Physical Anthropology 51:213-218.

Scott, J. H., AND N.B.B. Symons

1982 Introduction to Dental Anatomy, $7^{\text {th }}$ ed. London: Churchill Livingston.

Scott, G. R., And C. G. Turner II

1997 The Anthropology of Modern Human Teeth: Dental Morphology and its Variation in Recent Human Populations. Cambridge: Cambridge University Press.

Shapira, Y., AND P. DeLIVANIS

1982 Multiple-rooted mandibular second premolars. Journal of Endodontics 8(5):231-232.

Simpson, Ian A., Nikos Kourampas, and H. Nimal Perera

2008 Bellan-bandi Palassa, Sri Lanka: Formation process of a Mesolithic open-air site identified through thin section micromorphology. Archaeologia, Journal of Archaeology 4:3-18.

SMith, B. H

1984 Patterns of molar wear in hunter-gatherers and agriculturalists. American Journal of Physical Anthropology 63:39-56.

Somadeva, Raj, and Sudevi Ranasinghe

2006 An excavation of a shell-midden at Pallemalla in southern littoral area of Sri Lanka: Some evidence of a prehistoric Chenier occupation on c. 4th millennium BC. Ancient Asia 1:14-24.

Tomenchuk, J., AND J. T. Mayhall

1979 A correlation of tooth wear and age among modern Igloolik Eskimos. American Journal of Physical Anthropology 51(1):67-78.

Turner II, G. C.

1967 Dental genetics and microevolution in prehistoric and living Koniag Eskimos. Journal of Dental Research 46:911-917.

1969 Microevolutionary interpretations from the dentition. American Journal of Physical Anthropology 30:421-426. 
Turner II, G. C., C. R. Nichol, And G. R. Scott

1991 Scoring procedures of key morphological traits of the permanent dentition: The Arizona State University dental anthropology system, in Advances in Dental Anthropology: 13-31, ed. M. A. Kelley and C. S. Larsen. New York: Wiley-Liss.

Ubelaker, D. H.

1999 Human Skeletal Remains: Excavation, Analysis, Interpretation, $3^{\text {rd }}$ ed. Manuals on Archaeology 2. Washington: Smithsonian Institution.

WAHL, JOACHIM

(n.d.) Godawaya (Sri Lanka) - Excavation 2008, Trench A: Anthropological Investigation, unpublished report. Konstanz: Regierungspräsidium Stuttgart, Landesamt für Denkmalpflege.

WATSON, J. T.

2008 Changes in food processing and occlusal dental wear during the early agricultural period in northwest Mexico. American Journal of Physical Anthropology 135(1):92-99.

White, Timothy D., M. T. Black, and P. A. Folkens

2012 Human Osteology, $3^{\text {rd }}$ ed. New York: Elsevier.

WijeYAPALA, W. H.

1997 New Light on the Prehistory of Sri Lanka in the Context of Recent Investigations of Cave Sites. Ph.D. Thesis. Department of Archaeology, University of Peradeniya.

Wood, B. A., S. A. Авbott, and H. Uytterschaut

1988 Analysis of the dental morphology of Plio-Pleistocene hominids IV. Mandibular postcanine root morphology. Journal of Anatomy 156:107-139.

YAMADA, H.

1992 On the "Talonid" in Japanese lower molars. Shika Kiso Igakkai Zasshi [Japan Journal of Oral Biology] 34:15-24. 